\title{
Factors that are Associated with Readiness to Transition from Pediatric to Adult Health Care in Cystic Fibrosis
}

\author{
Lindsay A. Corman
}

Follow this and additional works at: https://researchrepository.wvu.edu/etd

\section{Recommended Citation}

Corman, Lindsay A., "Factors that are Associated with Readiness to Transition from Pediatric to Adult Health Care in Cystic Fibrosis" (2014). Graduate Theses, Dissertations, and Problem Reports. 7307. https://researchrepository.wvu.edu/etd/7307

This Dissertation is protected by copyright and/or related rights. It has been brought to you by the The Research Repository @ WVU with permission from the rights-holder(s). You are free to use this Dissertation in any way that is permitted by the copyright and related rights legislation that applies to your use. For other uses you must obtain permission from the rights-holder(s) directly, unless additional rights are indicated by a Creative Commons license in the record and/ or on the work itself. This Dissertation has been accepted for inclusion in WVU Graduate Theses, Dissertations, and Problem Reports collection by an authorized administrator of The Research Repository @ WVU.

For more information, please contact researchrepository@mail.wvu.edu. 
Factors that are Associated with Readiness to Transition from Pediatric to Adult Health Care in Cystic Fibrosis

\author{
Lindsay A. Corman, M.A \\ Dissertation submitted to \\ The Eberly College of Arts and Sciences \\ at West Virginia University \\ in partial fulfillment of the requirements \\ for the degree of \\ Doctor of Philosophy \\ in \\ Psychology
Christina L. Duncan, Ph.D., Chair
Cheryl B. McNeil, Ph.D.
Kevin T. Larkin, Ph.D.
Aaron Metzger, Ph.D.
Maple T. Landvoigt, M.D.

\author{
Department of Psychology \\ Morgantown, West Virginia
}

2014

Keywords: Cystic Fibrosis, transition, pediatric, psychosocial, hope Copyright 2014 Lindsay A. Corman 
UMI Number: 3618092

All rights reserved

INFORMATION TO ALL USERS

The quality of this reproduction is dependent upon the quality of the copy submitted.

In the unlikely event that the author did not send a complete manuscript and there are missing pages, these will be noted. Also, if material had to be removed, a note will indicate the deletion.

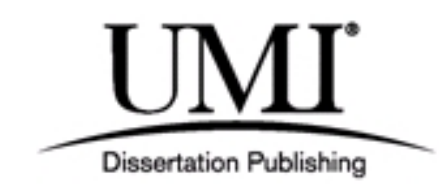

UMI 3618092

Published by ProQuest LLC (2014). Copyright in the Dissertation held by the Author.

Microform Edition () ProQuest LLC.

All rights reserved. This work is protected against unauthorized copying under Title 17, United States Code

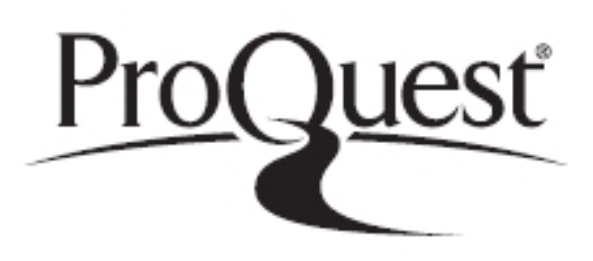

ProQuest LLC.

789 East Eisenhower Parkway

P.O. Box 1346

Ann Arbor, MI 48106 - 1346 


\begin{abstract}
Factors that are Associated with Readiness to Transition from Pediatric to Adult Health Care in Cystic Fibrosis
\end{abstract}

\title{
Lindsay A. Corman
}

Life expectancy of patients with Cystic Fibrosis (CF) has been increasing, with most children with CF expected to live at least into middle age adult years. Consequently, the majority of patients with $\mathrm{CF}$ will have to transition from a pediatric to an adult clinic. Unfortunately, few transition programs exist that attend to the physical, developmental, and psychological factors of adolescents with CF who need to transfer to adult clinics. Moreover, to date, there is a dearth of quantitative research that has been conducted to assess factors that may influence readiness to transition. The purpose of this study is to examine how specific psychosocial variables, such as locus of control, parental style, anxiety, and hope are associated with readiness to transition from pediatric to adult-centered health care for CF. A sample of 60 adolescents with CF (ages 14-20 years) and their caregivers were recruited from three pediatric clinics across the United States. Adolescents and caregivers each were required to complete a packet of questionnaires. Results revealed that age is positively correlated with youth and parents' ratings of transition readiness. Additionally, as hypothesized, youth reported higher readiness scores than their parents' ratings of the youth's readiness to transition. Further, the current study found that parental vicarious hope was significantly associated with increased youth-and parent-rated readiness to transition. Consequently, when developing transition programs, it may be beneficial to include methods to increase parents' level of hope for their child. Ultimately, future research is still needed to understand the potential role that a variety of psychosocial factors may play in adolescents' readiness to move from a pediatric to adult clinic, and will be essential in the continued development of CF transition programs across the country. 


\section{Acknowledgments}

I would like to thank my advisor and committee chairperson Dr. Christina Duncan for guidance in the design and completion of this study, as well as feedback on drafts of this manuscript. Christina has been a great mentor to me in both research and clinical matters, and has provided me with the skills needed to embark on my career as a psychologist. I wish to also thank my committee members for their time, feedback, and support. I am very appreciative of all the psychologists, doctors, nurses, RAs, and clinical teams at the three study sites, whose help and participation were essential in the completion of this project. Thank you to the youth and their families who participated in this research, making this study possible.

Thank you to my friends, who have supported and helped me through this process. There are countless moments of laughter and fun that I will always remember. A special thank you to my mother who raised me to believe that I could accomplish anything that I wanted to. Her encouragement and confidence in me is what carried me through. With loving thoughts of my late father, who instilled in me the importance of kindness and empathy. Finally, special thanks to my husband, for his continuing love, support, and for being my best friend. It is with much happiness and appreciation that I dedicate this manuscript to all of you. 


\section{TABLE OF CONTENTS}

Abstract........................................................................ ii

Acknowledgements...................................................... iii

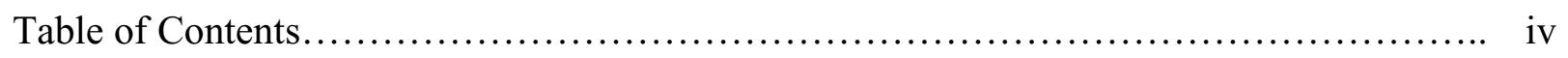

Introduction and Literature Review.............................................. 1

Background on Transition.............................................. 2

Cystic Fibrosis Transition................................................ 5

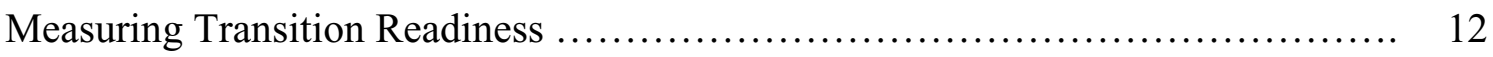

Possible Factors Related to Transition........................................ 13

Locus of Control................................................... 14

Hope.............................................................. 16

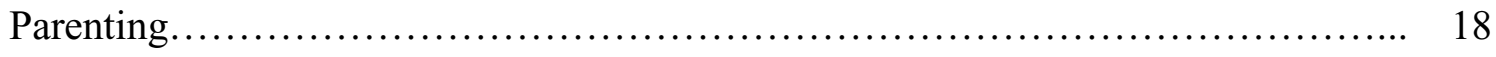

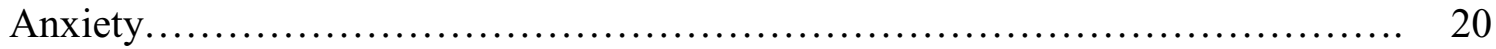

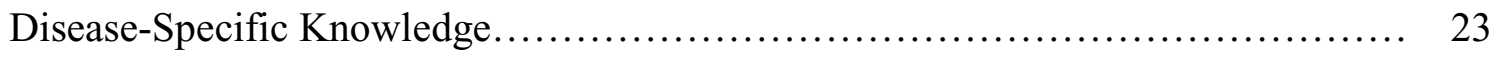

Purpose of Current Study .................................................. 24

Study Hypotheses..................................................... 26

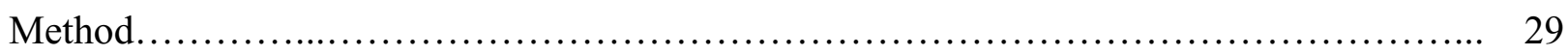

Participants........................................................ 29

Procedure........................................................ 29

Measures................................................... 30

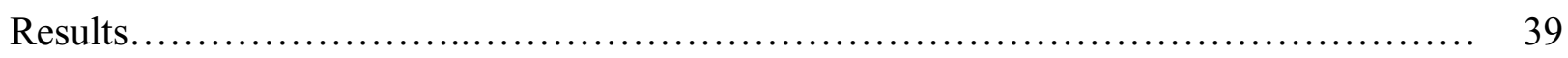

Power Analysis.................................................... 39

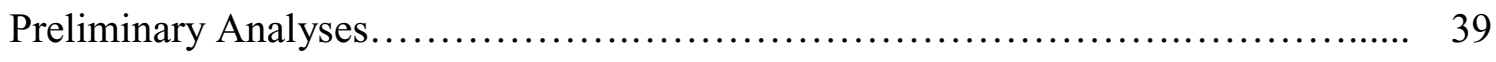

Descriptive Statistics................................................. 42

Major Analyses..................................................... 44

Exploratory Analyses................................................. 48

Discussion............................................................ 51

Examination of Proposed Hypotheses................................... 51

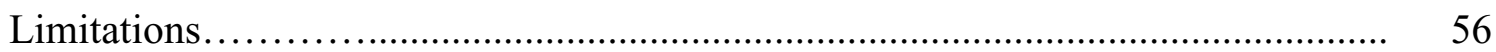


Future Directions............................................................ 58

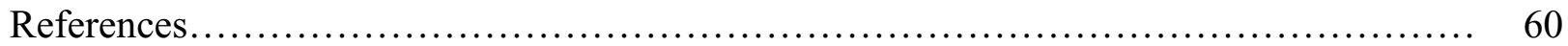

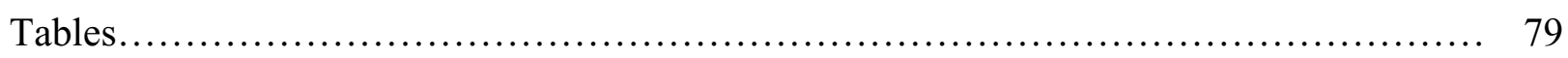

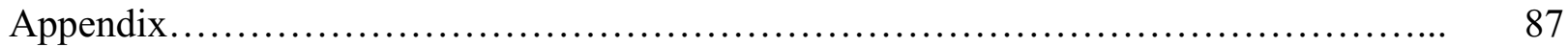


Factors that are Associated with Readiness to Transition from Pediatric to Adult Health Care in Cystic Fibrosis

Cystic Fibrosis (CF) is one of the most prevalent genetic diseases which leads to premature death, typically as a result of repeated cycles of pulmonary infections progressing to respiratory failure (Simmonds, Cullinan, \& Hodson, 2009). CF is an autosomal recessive disease caused by a mutation in the CF transmembrane conductance regulator (CFTR) gene located on Chromosome 7, and more than 1500 CFTR mutations have been identified (O'Sullivan \& Freedman, 2009). Researchers found that mutations in the CFTR gene disrupt the function of the chloride channel, preventing the usual flow of chloride ions and water into and out of cells (Welsh \& Smith, 1995). This disruption in the function of the chloride channel leads the body to produce thick and sticky mucus. The thick mucus prevents proper functioning of multiple organs, including the lungs and the pancreas, which results in pulmonary infections and the body's inability to break down and absorb nutrients (Strausbaugh \& Davis, 2007). Thus, although pulmonary complications are the leading cause of death in individuals with CF, many other organ systems also are affected.

There are approximately 30,000 individuals in the United States who currently have CF (Strausbaugh \& Davis, 2007). Specifically, the disease occurs in roughly 1 in 3,000 white Americans, 1 in 4,000-10,000 Latin Americans, and 1 in 15,000-20,000 African Americans (Walters \& Mehta, 2007). Because more than 1500 different CFTR mutations exist, as well as many other disease modifying genes, there are different disease phenotypes with great variability of symptoms, disease severity, and rate of health deterioration from patient to patient (O'Sullivan \& Freedman, 2009). Diagnosis is made by clinical and laboratory evaluation (Strausbaugh \& Davis, 2007). Most cases of CF are identified during childhood with approximately $60 \%$ of cases of CF being diagnosed by the time the child is one year of age. The most common and readily 
available way of making the diagnosis of CF is the sweat test, which measures the quantity of chloride in a sweat sample (Wiehe \& Arndt, 2010).

Presently, there is no cure for CF; consequently, patients are required to adhere to a multi-component treatment regimen in order to maintain optimal health across their life span. Specifically, the three main components of treatment include: chest physiotherapy (CPT) at least twice daily, along with multiple nebulized mucolytics (to expectorate excess mucus in the airways and reduce infection potential); pancreatic enzyme supplements (ES) with all meals and snacks (to increase nutrient absorption) for most patients; and, routine courses of oral or nebulized antibiotics (Bucks et al., 2009). Even with treatment, many patients with CF experience a progressive deterioration in health, leading to a shortened median predicted survival age of roughly 37 years (O’Sullivan \& Freedman, 2009). However, this median age is a substantial improvement from 1938 when CF was first identified as a specific disease and over $70 \%$ of patients died in their first year of life (Simmonds et al., 2009). Because research over the years has led to a better understanding of CF and consequently there have been substantial improvements in treatment and care, the majority of children diagnosed with CF now live well into adulthood (Dugueperoux et al., 2008). Indeed, Simmonds et al. (2009) state that children born in the beginning of the $21^{\text {st }}$ century are now predicted to have a median survival into their 50's, and there are now more adults with CF than children in many countries. Thus, many children with CF will require adult-oriented medical care during their lifetime.

Transition in a medical setting is described as a process that includes the movement of an adolescent or young adult from pediatric to adult-oriented health care (Tuchman, Schwartz, Sawicki, \& Britto, 2010). Transition definitions in the literature have included various components, such as provider-focused (e.g., engaging young adults in age-appropriate medical 
care), patient-focused (e.g., individual's medical skill and knowledge acquisition), and a developmental perspective (e.g., individual's level of responsibility, decision-making ability) (Tuchman et al., 2010). The improved prognosis for patients with CF presents a crucial need to address transition issues and to provide age-appropriate care (Dugueperoux et al., 2008). Specifically, the increased life expectancy for patients with CF brings about the need for both patients and the professionals who provide medical and psychosocial services to them, to expand, evolve, and tailor their treatment approaches into adulthood (Palmer \& Boisen, 2002). For example, older patients with CF must be responsible for their treatment regimens, while they finish school, join the workforce, marry, and start families (Dugueperoux et al., 2008). Accordingly, an adult with CF will have very different medical, psychosocial, and developmental needs than a child with CF; thus, they would benefit from health care professionals who understand how to manage their specific issues.

Many CF transition programs have been implemented; however, there are no collective consensuses or guidelines on the best method of transition for patients with CF (Webb, Jones, \& Dodd, 2001). For example, the University of Michigan's CF Center's transition program includes a discussion of the process with the family and pediatric team, a clinic visit with both the pediatric and future adult medical team members, and a tour of the adult facilities (Chaudhry, Keaton, \& Nasr, 2013). Similarly, adult care providers at Boston Children's Hospital introduce themselves to the patient and family when an adolescent is $16-17$ years, prior to transfer to adult care at age 18 (www.childrenshospital.org). Contrarily, at Miller Children's Hospital Long Beach, transition preparation begins early and consists of clinical assessment of the adolescent's self-management skills, construction of a personal transitional plan of care, and youth and parent education sessions and counseling (http://www.millerchildrenshospitallb.org/centers- 
programs/transitional-care-program). Finally, at Riley Hospital for Children in Indianapolis Indiana, transition preparation begins at age 12 and includes discussion, transition checklists, a DVD on transition, and independent visits for the patient beginning at 13 years of age.

Ultimately, there are many transition programs currently implemented, but there are no shared procedures or guidelines on what should be included in the transition programs. Taken together, this illustrates the need to develop further and utilize transition programs that address physical, developmental, and psychological factors that are associated with a successful transfer to adultoriented health care.

There are unique challenges encountered with transition that make it difficult to establish general guidelines. For instance, patients and parents do not want to lose the often longstanding relationships with their pediatric health care professionals, and parents want to remain in control of their child's treatment and decisions, given its relation to their child's longevity. Similarly, pediatricians may be reluctant to release a patient due to beliefs that they know the patient best and should continue to manage the patient's health care as well as their awareness that there is a general lack of established adult CF centers (Anderson, Flume, Hardy, \& Gray, 2002). This explains the finding that approximately $25 \%$ of adults with CF remain in pediatric CF clinics, even though the Cystic Fibrosis Foundation's guidelines suggest transition to adultcentered health care (www.cff.org). Previously, CF transition policy mainly concentrated on the actual transfer process, including the credentials of the multidisciplinary team, rather than on the content of transition programs (e.g., addressing developmental and psychological factors of transition) (Yankaskas, Marshall, Sufian, Simon, \& Rodman, 2004). For current pediatric patients to make a smooth and successful shift into adult health care, a transition program needs to be implemented in all CF health care settings. Although the importance of transition programs 
is acknowledged by health care professionals, and given the fact that many transition programs have already been implemented, little is known about the psychosocial aspects that make transition successful (Tuchman et al., 2010).

\section{CF Transition}

The majority of research focusing on CF transition has been qualitative in nature (e.g., Berge, Patterson, Goetz, \& Milla, 2007; Boyle, Faruki, \& Nosky, 2001; Dupuis, Duhamel, \& Gendron, 2013; Iles \& Lowton, 2008; Iles \& Lowton, 2010; Moola \& Norman, 2011; Tuchman, Slap \& Britto, 2008; van Staa, Jedeloo, van Meeteren, \& Latour, 2011). Specifically, many of the published studies on the transition process of young adults with CF reported qualitative outcomes, such as satisfaction and perception of transition based on focus group interviews and non-validated questionnaires. For example, Iles and Lowton (2008) interviewed 50 patients with CF (13-24 years) about their expectations or experiences of transition care from two transition centers in England. Their results revealed that the three main concerns patients discussed in relation to their apprehension about transition were (a) how relocating to cities for work or school would impinge on their access to an adult health care professional; (b) the impact of CF on their present and future intimate relationships, particularly surrounding their fertility; and (c) their future health problems, such as organ transplantation and reduced life expectancy. Thus, this study illustrates some predominant concerns of patients with CF regarding transition, but is unable to elucidate individual psychosocial factors associated with degree or type of concern, or exactly how these concerns create problems in the transition process.

Similarly, Westwood, Henley, and Willcox (1999) state that there are indeed significant concerns about the transition process within the CF population. Specifically, using a semistructured survey, these researchers examined 47 patients with CF (aged 14-21 years) and their 
parents from a pediatric CF clinic and an adult CF clinic about their attitudes towards growing up, transferring clinics, and the transition process. Results showed that the majority of adolescents expressed fear or apprehension about transition. The main reason for this apprehension was because the adolescents feared that they would not like the adult clinics. Many participants stated that a structured transition program would alleviate much of their worry and concerns. Although it used a small sample size and qualitative survey, this study reiterates the importance of structured transition programs to help adolescents make a smooth and successful transfer to adult care.

Moreover, Berge et al. (2007) assert that not only are there major concerns about the transition process, but that there are also gender differences in factors related to transition. Using focus groups with patients aged 17-22 years, the researchers found that females reported completing more treatments per day than males. Second, females indicated that having someone to whom to be accountable influenced their treatment adherence, whereas males did not express this need. Third, female patients with CF reported more depressive symptomatology and body image issues than males. Finally, males reported more risk-taking behaviors, such as smoking, drinking, and using drugs. Both genders reported concerns regarding acquiring other chronic conditions, such as diabetes. Furthermore, Moola and Norman (2011) stated that their study revealed that young women with CF feel the loss of "normal" gendered roles, expressing sorrow that their illness would affect their ability to have children and to experience a typical pregnancy. Together, these articles illustrate a few of the mental health issues and gender differences that health professionals need to address during the transition process. However, these studies also exemplify that there is a need for research using objective measures to further assess these relevant psychosocial factors (e.g., depression, body image, risk-taking) because it is possible 
that these factors could affect the transition process. For instance, if female patients are experiencing depressive symptoms, then they may not have the motivation, desire, or energy to take responsibility for their own treatment regimen, attend clinic, or follow proper nutrition and exercise recommendations.

Finally, Iles and Lowton (2010) examined CF patients' perceptions of parental support during and after transition to adult services. Specifically, the researchers conducted semistructured interviews with 50 patients with CF (ages 13-24) and 23 healthcare professionals in two CF centers in Southeast England to assess how young adults and staff view parental support during the transition process. Their results revealed 4 categories of perceived parental support, including parents as financial, practical, and emotional supporters; parents as "troubleshooters" in times of health-related crisis; parents as partners in ongoing disease management in the home and clinic; and parents as "protectors" of their child from CF-related distress. Additionally, patients and health care professionals reported that parental anxiety and over-involvement was adverse to and led to views of unsupportiveness. Therefore, this qualitative study indicates that parental support and involvement play a crucial role in transition to adult health care for young patients with CF. However, this study focused solely on perceived health-related support; thus, it would be interesting to examine the importance of other types of perceived support (e.g., emotional and social) on adolescents' transition to adult care.

Although not as commonly used as qualitative methods, some researchers have used quantitative measures to examine factors related to transition from pediatric to adult-oriented health care in patients with CF (e.g. Cappelli, MacDonald, \& McGrath, 1989; Craig, Towns, \& Bibby, 2007; Ievers et al., 1999; Marciel, 2008; McLaughlin et al., 2008; Sawicki, et al., 2009; Siklosi, Gallagher, \& McKone, 2010). Specifically, a few researchers have developed and 
validated measures that can be utilized to investigate factors related to transition. For instance, Siklosi and colleagues (2010) used a sample of 100 patients with CF (ages 17-49) to develop a CF knowledge questionnaire evaluating comprehension of critical components of the disease, such as cause, complications, lung and gastrointestinal involvement, genetics, and reproduction. Findings led the researchers to conclude that the measure displayed acceptable internal consistency and criterion validity, and good test-retest reliability. This study was conducted with an Irish sample, which could affect the study's generalization to a North American population. Nevertheless, the findings suggest that the development of a measure assessing general CF knowledge can be a useful tool to investigate patients' level of comprehension and their knowledge deficits regarding their disease as they begin the process of transition.

Another useful assessment tool that has been developed and validated is the Transition Readiness Assessment Questionnaire (TRAQ; Sawicki et al., 2009). Using non-validated questionnaires or checklists from transition programs, the authors identified specific behaviors pertinent to healthcare transition, such as managing health, interacting with health care providers, and carrying out activities of daily life independently (e.g., finances, education, employment, etc.). Next, the authors formulated questions to assess those skills and administered the TRAQ to 192 youth across three different areas of importance: Activity Limiting Physical Condition (e.g., cystic fibrosis, cerebral palsy, deafness, sickle cell disease, or other chronic conditions which mainly affect the physical health of the patient), Cognitive Impairment (e.g., Autism Spectrum Disorder, or mild mental retardation, or youth who had some degree of impairment, but who were able to complete questionnaires independently), and Mental Health Condition (e.g., attention-deficit hyperactivity disorder, learning disabilities, behavior disorders, bipolar disorder, or other mental health conditions which may influence an individual's ability to master skills 
related to transition). Results of the analysis revealed two TRAQ domains with high internal consistency: Skills for Self-Management (e.g., "Do you take medications correctly and on your own" and "Do you know what your health insurance covers") and Skills for Self-Advocacy (e.g., "Do you answer questions that are asked by the doctor, nurse, or clinical staff" and "Do you request and get the accommodations and support you need at school or work"). Although this study was not conducted exclusively on a sample of patients with $\mathrm{CF}$, it still provides a potentially useful measure to assess "readiness," specifically the individual's skills in selfmanagement and self-advocacy, before, during, and after transition.

Even with the development of these measures, there have been few published studies that have utilized these or other empirically validated instruments to assess the CF transition process. Bloom and colleagues (2012) completed a systematic literature review on transition for youth with special health care needs, and they concluded that the majority of the research has been completed outside the United States, and because of the differences in health care structure and health insurance, it may limit the generalizability of findings to the United States. Additionally, the authors state that there is a lack of evidence regarding transition to adult health care, and consequently, there is a need for quantitative research on the essential components of effective transition programs to replace the anecdotal program reports of satisfaction with transition programs. The studies that have included validated assessment measures or quantitative outcome data are as follows. First, Craig et al. (2007) conducted a transition program evaluation using a cross-sectional design composed of a group of patients with CF and their parents who had not begun the transition process $(\mathrm{N}=90)$ and a similar group who had finished the transition program $(\mathrm{N}=47)$. Participants completed self-report questionnaires evaluating their concerns, level of participation, satisfaction with transition, and quality of life, while measures of disease 
severity (e.g., lung function tests and body mass index) were obtained from participants' medical records. Results revealed that the majority of patients and parents who had finished the transition program were satisfied with the transition process and that the more that they were involved in the program, the more their satisfaction increased. Additionally, in the pre-transition group, the youth with CF had fewer concerns about the transition process than their parents. However, there was no evidence of a relation between amount of participation in the transition program and measures of disease severity or quality of life. Although the study did not match the pretransition and post-transition groups on age, gender, or disease severity, which limits comparative conclusions of the two groups, the results still highlight that the transition process can become increasingly more positive with higher levels of participation in a transition program.

Next, researchers developed and validated a survey for comprehensive assessment of transition practices in CF care. In fact, the study conducted by McLaughlin and colleagues (2008) included data from $87 \%$ of all Cystic Fibrosis Foundation (CFF) accredited programs across the United States, with input from 448 of their providers. In order to assess factors related to successful transition, it is important to understand the current transition practices that have been implemented. Findings revealed that transfer occurs at a median age of 19 years, and initial discussion of transition does not occur until the patient is approximately 17 years old (McLaughlin et al., 2008). Additionally, results showed that only $50 \%$ of CF programs regularly perform readiness assessments. Most importantly, less than $10 \%$ of CF clinics had a written list of desirable self-management skills (e.g., ability to list medications, take medication/perform airway clearance without being reminded, and contact insurance company) to signal readiness for transition. The researchers asserted the importance of patients developing self-management 
skills to make a smooth transition to adult health care where they will independently care for themselves. However, only one study (Marciel, 2008) to date has attempted to examine factors that may influence the rate or the ability of patients to develop the essential skills needed for a positive transition.

Marciel (2008) conducted a study with 50 pediatric and 10 adult patients with CF from four CF centers across the eastern United States. Specifically, the aim of the study was to adapt a patient self-report questionnaire of self-care independence, measure possible correlates of selfcare independence in patients with $\mathrm{CF}$, and quantitatively investigate variables related to transition readiness. Results revealed that the self-report measure of self-care independence demonstrated good internal consistency, moderate test-retest reliability, and weak concurrent correlation with patients' knowledge of CF. Additionally, the author did not find that self-care independence was significantly related to target variables used (e.g., executive functioning, family functioning, or parental distress). Moreover, self-care independence did not account for any of the variance in ratings of readiness to transfer from pediatric to adult care. This lack of relation, however, may have stemmed from the limitations of the measure used (e.g., adapted measure was found to have a lack of discriminant validity, such that it failed to discriminate between pediatric and adult patients). Although this study had a small sample size and did not find many significant results, it is still the first study that evaluated variables related to readiness to transfer to adult-oriented CF centers. Thus, it lays the groundwork for future research to develop and test additional theories that broaden the understanding about the factors that potentially influence patients' readiness to transfer healthcare. 


\section{Measuring Transition Readiness}

Ultimately, there is a lack of evidence-based CF transition programs, as well as an absence of collective guidelines to determine the best procedures and appropriate content to use when implementing a CF transition program. First, to determine whether psychosocial factors are associated with readiness to transition, a measure assessing readiness needs to be included. A review of literature revealed that there are very few validated measures to assess transition readiness. In fact, criteria for transfer from pediatric to adult care most often rely solely on age, but there is a need to examine the developmental process of readiness to transfer to adult health care (Sawicki et al., 2009). As mentioned above, Sawicki and colleagues (2009) developed and validated the TRAQ, which assesses two domains of transition, which include skills for selfmanagement (e.g., managing medication, medical appointments, and health insurance) and skills for self-advocacy (e.g., communication with medical team, community support services, and financial assistance). These skills are essential for adolescents with $\mathrm{CF}$, as well as youth with other chronic illnesses. For example, a study of young adults with congenital heart disease revealed that attending appointments alone and arranging follow-up appointments was associated with successful transfer to adult care (Reid et al., 2004). Moreover, studies have found that lack of self-management skills has been correlated with worse outcomes in youth with diabetes (Bryden, Dunger, Mayou, Peveler, \& Neil, 2003; Karlsson, Arman, \& Wikblad, 2008). Furthermore, the TRAQ assesses the youth's ability to manage their insurance, which is a critical component for transition to adult health care, because patients need to know how their care will be paid for when they reach the age where they are responsible for their own medical bills. (Callahan \& Cooper, 2005). Thus, if adolescents with chronic illness have skills to maintain insurance, it will likely increase their ability to make a smooth transition to adult health care. 
Ultimately, the TRAQ measures multiple developmental skills that are relevant to youth with chronic illness who are transitioning from pediatric to adult health care.

Additionally, although no studies to date have examined concordance in youth and parent ratings of readiness, studies have investigated concordance rates between youth and parents for reports of adherence to medical regimens. For example, Babyar (2010) found that youth reported greater levels of adherence than their parents for airway clearance and aerosol medication adherence. Studies have shown that youth may be influenced by degree of social desirability when answering self-report questionnaires (Coutts, Gibson, \& Paton, 1992; Marhefka, Tepper, Farley, Sleasman, \& Mellins, 2006). Not surprisingly, Drotar (2000) suggests collecting adherence information from multiple sources to minimize individual bias. In sum, these studies imply that there is value in assessing different informants' reports of readiness to transition. Indeed, if results reveal a discrepancy between youth and parent ratings, then it will be an important factor to consider when designing transition programs.

\section{Possible Factors Related to Transition}

To develop CF transition programs that provide young adults with the capability to move successfully to adult care and independent lives, research needs to establish what behaviors and issues should be targeted within the transition process. Although there are many factors that may be associated with readiness to transition, the ones in this study were chosen based on the integration of a review of relevant literature and some observations made in a CF clinic. In particular, there have been numerous studies on how specific psychosocial variables, such as locus of control, parental style, anxiety, and hope are associated with psychological adjustment, adherence, general functioning, attachment, and other aspects of chronic illness, including CF. Because adjustment, adherence, and general functioning are important components to patients 
being able to move to adult care where they will be required to be fully responsible for their disease management, then it is possible that those psychosocial factors, as well as potential disease-related factors (e.g., knowledge) may be associated with readiness to transition.

\section{Locus of Control}

Locus of control (LOC) is described as an individual's self-perception of control over events in their lives. Roddenberry and Renk (2010) explain Rotter's (1966) theory as “the degree to which individuals feel that rewards are contingent on their own behavior or, in contrast, are controlled by forces outside of themselves determines their own self-perceptions of control in a given situation" (p. 354). Specifically, individuals who have an external LOC perceive that control is outside of them and life events are due to luck, fate, chance, or in the hands of a powerful other. In contrast, individuals who have an internal LOC perceive events as contingent upon their own behavior (Roddenberry \& Renk, 2010). Health-related LOC is conceptualized similarly. First, internal health-related LOC is the degree to which individuals perceive themselves to be in control of their own health. Second, chance health-related LOC is the degree to which individuals perceive that their health is controlled by chance, fate, or luck. Finally, powerful others health-related LOC is the degree to which individuals perceive that other powerful people, such as doctors or nurses, control their health (Roddenberry \& Renk, 2010). Smith, Dobbins, and Wallston (1998) argue that internal health-related control is positively correlated with healthy psychological adjustment, positive health behaviors, and better heath. On the contrary, chance health-related LOC is correlated with negative health behaviors and poor psychological adjustment. Consequently, health-related LOC may play an important role in motivation, outlook, and other factors that could influence an individual's readiness to transfer from pediatric to adult health care. 
Although no studies to date have focused on how health-related LOC is associated with transition, many studies have examined how LOC is associated with different aspects of chronic illness. For example, Neipp, Lopez-Roig, and Pastor (2007) reviewed articles that were published between 1966 and 2006 that evaluated the relation between perceived control and health outcomes in adults with cancer. The results from the studies varied, but overall the internal dimension of LOC was associated with better emotional status and quality of life than the chance dimension. In addition, Neipp and colleagues (2007) concluded that the studies showed that patients who perceived their health to be under the control of chance were not as well adjusted to the illness. However, the relation between the powerful others LOC and health outcomes in cancer patients is ambiguous. Specifically, results from various adult studies found that it was related either to better adaptation or worse adaptation (e.g., Andrykowski \& Brady, 1994; Blood, Dinee, Kauffhian, \& Raimondi, 1993; Lowery, Jacobsen, \& DuCette, 1993), whereas a couple of studies found no association at all (Arraras, Wright, Jusue, Tejedor, \& Calvo, 2002; Bourjolly, 1999). Moreover, a LOC profile that includes high scores in both internal control and external powerful others control, as well as low scores in chance healthrelated control, has been shown to be related to better adjustment in adult diabetes patients (Bradley, Lewis, Jennings, \& Ward, 1990).

LOC also has been examined in the CF population. Meyers and Meyers (1999) conducted a study with 31 adult patients with CF that examined the association between LOC and selfreported treatment adherence. Using an empirically validated health LOC scale, the researchers found that good adherence was associated to external control, especially the powerful others subscale. Moreover, a study using children (aged 7-12 years) with CF or sickle cell disease found that internal LOC was associated with better adjustment (Thompson, Gustafson, Gil, Godfrey, \& 
Bennett-Murphey, 1998). Finally, a study investigating level of responsibility for disease-related tasks and health LOC in a sample of 75 adults with CF found that those individuals who were more engaged in treatment adherence endorsed a higher internal LOC (Hamlett, Murphy, Hayes, \& Doershuck 1996). The authors suggest that because the treatment regimens for CF are more frequent and time-consuming than those for other illnesses, then individuals who believe that they are in control of their disease are more likely to be adherent. Furthermore, their results also revealed that the participants rated high beliefs in the effect that powerful others have on their health. However, powerful others control was not related to adherence as it was in Meyers and Meyers (1999) study. This discrepancy could be the result of the location and method of each study; Meyers and Meyers conducted their study in the United Kingdom and used the conditionspecific scale of the Multidimensional Health Locus of Control Scale (MHLC-C), whereas Hamlett et al. (1996) conducted their study in the United States and used the general scale of the MHLC-C.

Overall, health LOC appears to be an important factor for psychological adjustment, emotional well-being, and taking individual responsibility for the treatment regimen. Thus, adolescents' self-perception of control may be related to their level of responsibility and motivation toward following their regimen, which in turn might impact their readiness to transfer to more independent adult-based medical care.

\section{Hope}

Hope has been regarded as a crucial and fundamental component in human life and health (Kim, Kim, Schwartz-Barcott, \& Zucker, 2006). Snyder, Irving, and Anderson (1991) define hope as "a positive motivational state that is based on an interactively derived sense of successful (a) agency (goal-directed energy) and (b) pathways (planning to meet goals)" (p. 287). An 
optimistic approach has been found to be related to better health status in many illnesses. In particular, a positive outlook has been reported to lead to better coping of everyday stressors (Anbar \& Murthy, 2010). Transition to adult-oriented health care can be viewed as a stressful life event; consequently, hope could affect how well patients with CF cope with the change in medical care. Moreover, hope for the future could be a key aspect in an individual's desire to begin the developmental tasks of adulthood (e.g., independent living, self-financing, etc). Thus, transitioning to an adult-oriented clinic would be a logical and necessary step for those youth who hope for longevity and want to achieve adult independence.

As with locus of control, no study to date has assessed how hope is associated with transition for adolescents with a chronic illness. However, many studies have been conducted that measure hope with other factors of having a chronic disease, which may relate to transition. For example, in an investigation with sickle cell disease, the researchers stated that higher levels of self-reported hope predicted greater use of active coping strategies, which subsequently predicted positive outcomes (i.e., less anxiety) (Lewis \& Kliewer, 1996). Furthermore, Maikranz, Steele, Dreyer, Stratman, and Bovaird (2007) completed a study with 70 pediatric renal and liver transplant recipients and their caregivers, which examined the relation among hope, illnessrelated uncertainty, anxiety, depression, and medication adherence. The results showed that lower levels of hope and higher levels of uncertainty were significantly associated with both depressive symptoms and anxiety, and depressive symptoms were significantly related to adherence. Thus, the authors conclude that their results support the view that hope is indirectly related to treatment adherence through its direct relation with depressive symptoms. Because treatment adherence is a major aspect of transition to adult health care for the CF population, 
given the issues of promoting independence and responsibility, it consequently seems important to consider hope as a potential factor in readiness.

Not only is hope important for the patient, but it also is important for the caregiver. Wong and Heriot (2007) examined how vicarious hope (e.g., parents' beliefs that good things will happen in their child's future) and vicarious despair (e.g., parents' belief that bad things will happen in their child's future) was associated with parental coping, parental adjustment, and child psychological adjustment. Specifically, the researchers used empirically validated selfreport measures with a sample of 35 parents who had children with $\mathrm{CF}$, and concluded that vicarious hope and vicarious despair were related to child and parental psychosocial adjustment. In particular, the researchers stated that vicarious despair predicted parental anxiety and child maladjustment. These findings, coupled with the logical point that hope for a child's future would underlie parents' willingness to support their child's transition to adult care, suggests that this should be a key variable to consider when examining a family's readiness for transition.

\section{Parenting}

The parent-child relationship is one of the most important attachments for a child, and serves as an essential element for a child's psychological and physical growth (Gladstone \& Parker, 2005). Parenting is a multifaceted set of behaviors and can be influenced by many factors, such as presence of parental psychopathology (Parker \& Lipscombe, 1981), parental neurobiological factors (Maestripieri, 1999), intergenerational effect of child rearing practices (Miller, Kramer, Warner, Wickramaratne, \& Weissman, 1997), and religious factors (Luft, 1987). Parenting style has been described and measured in relation to the extent and amount of warmth and care as well as overprotection and control that the parent exhibits toward their child (Parker, Tupling, \& Brown, 1979) 
Research has revealed that parental style, such as overprotection and warmth, is associated with a child's adjustment to a chronic health condition (Bourdeau, Mullins, Carpenteir, Colletti, \& Wolfe-Christensen, 2007). In fact, a study found that parents of children with a chronic illness reported more overprotective behaviors than parents of healthy children, and that overprotection was associated with increased internalizing and externalizing behavior problems in these children (Holmbeck et al., 2002). Therefore, parenting style may have a considerable association with the psychological and emotional adjustment of children and adolescents with chronic illness.

In fact, Agostini et al. (2010) conducted a study with 102 patients with Crohn's disease (CD) and 306 healthy controls, and compared their self-reported attachment style and early parental experience. Their results indicated that those individuals with $\mathrm{CD}$ were significantly more likely to report having an insecure attachment style than the healthy control group. Additionally, individuals with CD described their parents' rearing style as having lower maternal care and higher paternal protection. The researchers concluded that patients with CD describe a lack of warmth and understanding in the relationships with their mothers and a lack of independence and self-sufficiency in their relationships with their fathers. Agostini et al. (2010) explain that international research is beginning to link insecure attachment to illness. Specifically, patients with chronic illness have been found to have a higher prevalence of insecure attachment. This is consistent with the results of a study that found that children with CF had a higher occurrence of insecure attachment than healthy controls (Simmons, Goldberg, Washington, Fischer-Fay, \& Maclusky, 1995). Furthermore, Cappelli and colleagues (1988) state that the majority of the literature has shown that parents and families of children with CF have been found to have considerable emotional and general functioning problems. They conducted a 
study with 36 children with CF to determine if parent, family, and disease factors could predict their psychosocial functioning. The results demonstrated that higher levels of maternal worry and overprotection predicted a higher number of behavior problems exhibited by the child. Although this study used a small sample, it reinforces the importance of the association of parental style with child behavior. It is possible that some parents of children with CF could be more overprotective and less encouraging of their child's independence than parents with healthy children, given the implications of ineffective disease management. It is also possible that adverse parenting could affect the behavior and adjustment of adolescents, which, in turn, could impact their readiness to transfer. Therefore, parental style would be an important factor to examine to determine if there is an association with youth's readiness to transition.

\section{Anxiety}

Adolescence and transition to young adulthood is a demanding phase of life for individuals with or without a chronic illness. It is a period of life involving increased independence, development of new relationships, identity formation, and plans for future educational or career paths. This developmental stage can be even more stressful and difficult for those individuals with a chronic illness (O’Donohue \& Woodward-Tolle, 2009). Thus, it is not surprising that studies have found that individuals with a chronic illness are at a higher risk for developing an internalizing disorder, such as depression and/or anxiety, during this phase of life (e.g., Gortmaker, Walker, Weitzman, \& Sobol, 1990; Greydanus, Patel, \& Pratt, 2010; Pao \& Bosk, 2011; Seigel, Golden, Gough, Lashley, \& Sacker, 1990; Weiland, Pless, \& Roghmann, 1992). For example, Woodgate (1998) conducted a qualitative study (i.e., open-ended interviews) with a sample of 23 adolescents who were diagnosed with a chronic health condition (e.g., diabetes, Crohn's disease, arthritis). These youth reported that their lives were more 
difficult because of extra effort, restriction in activities, pain, and worries. Their worries included that (a) they may develop complications because of their illness; (b) they may be limited in career choices because of their illness; and (c) future employers may not tolerate their use of sick-days. Moreover, Pao and Bosk (2011) reported that the prevalence rate of anxiety disorders is much higher among adolescents with chronic illnesses versus healthy comparison groups.

Unfortunately, the literature reveals similar results for adolescents with CF (e.g., Boyle, di' SantAgnese, Sack, Millican, \& Kulczyckzi, 1976; Drotar, 1978; Thompson et al., 1998). For instance, one study (Modi, Driscoll, Montag-Leifling, \& Acton, 2011) assessed 59 adolescents at their routine CF clinic visit, using the Hospitalized Anxiety Depression Scale (HADS). Their results revealed that $32 \%$ of the sample reported mild to severe anxiety symptoms. Moreover, Thompson and colleagues (1998) found that anxiety diagnoses were the most frequent psychological diagnoses for their sample of 40 pediatric patients with CF (ages 7-12 years). Finally, a study (White, Miller, Smith, \& McMahon, 2009) was conducted with 53 participants with CF between the ages of 9-17 using the Computer-aided Diagnostic Interview Schedule for Children $(C-D I S C)$ and the $C$-DISC parent report for their caregivers. Their results showed that $30 \%$ of the participants with CF met self-reported diagnostic criteria for an anxiety disorder and that $53 \%$ of the parents indicated that their child had an anxiety disorder.

In sum, there appears to be an increased risk and higher prevalence rate of anxiety symptoms in individuals with CF, which makes it an important factor to consider when studying transition readiness. Research on how anxiety may impact children and adolescents in general has shown that those who are anxious may have problems with concentration (Kendall \& Pimentel, 2003) problem-solving (Emerson, Mollett, \& Harrison, 2004), and forgetfulness (Jarrett \& Ollendick, 2008). These findings may be even more salient for children with a chronic 
illness. Indeed, Herzer and Hood (2010) found that in their sample of 276 adolescents with type 1 diabetes, those individuals with higher state anxiety were found to have less frequent blood glucose monitoring and suboptimal glycemic control. Additionally, Rosina, Crisp, and Steinbeck (2003) conducted a study with 44 adolescents and young adults with a chronic illness (e.g., cancer, $\mathrm{CF}$, asthma) and found that those individuals who reported higher internalizing symptoms, including anxiety and depression, were found to report lower treatment adherence. This finding illustrates the importance of examining anxiety, as it may influence adolescents' ability to manage their own health care and obtain autonomy. Additionally, anxiety symptoms may make it harder for individuals to leave their pediatric clinic, where they are familiar and comfortable with the routines, physicians, nurses, and other staff.

In addition, parental anxiety also has been found to impact children. For example, studies have found that anxious mothers are less warm in interactions with their children and do not allow their children to have as much autonomy as non-anxious mothers (e.g., Whaley, Pinto, \& Sigman, 1999; Woodruff-Borden, Morrow, Bourland, \& Cambron, 2002). Additionally, Moore, Whaley, and Sigman (2004) assert that anxious mothers model a fearful cognitive style, which may be observed and emulated by their child. Moreover, a study assessed how parental psychological distress and perceived child vulnerability related to anxiety in adolescents who were diagnosed with type 1 diabetes mellitus or asthma (Lopez, Mullins, Wolfe-Christensen, \& Bourdeau, 2008). The researchers concluded from their results that higher levels of parental psychological distress and perceived child vulnerability were associated with higher levels of anxiety in the adolescent. More specifically, results displayed a significant mediation model, where perceived child vulnerability mediated the relationship between parental distress and adolescent anxiety. Lopez and colleagues (2008) suggested that those parents with higher levels 
of distress might perceive their child as more vulnerable, which leads their child to develop anxiety symptoms. Therefore, parents with higher levels of anxiety and distress interact with their child differently than parents with lower levels of anxiety and distress. If anxious and distressed parents grant their children with $\mathrm{CF}$ a lesser amount of autonomy and confidence, this may affect the adolescent's readiness to transition.

\section{Disease-Specific Knowledge}

Those individuals diagnosed with a chronic illness will need to learn specific details about their disease, such as type of medications needed, what optimal treatment regimens are required, genetics, and reproductive issues. Regrettably, many individuals do not have a high level of disease-specific knowledge. For example, Chapman and Bilton (2004) assessed level of knowledge by administering semi-structured interviews to 26 individuals with CF (ages 18 to 48). The results of their study showed that many individuals with CF had a relatively low level of knowledge about their disease. Moreover, Henley and Hill (1990) used a cross-sectional survey to assess CF knowledge with 63 families who had a child diagnosed with CF. Specifically, they assessed 60 mothers, 54 fathers, 29 siblings (ages 10 to 23), and 18 patients (ages 9 to 22). The researchers stated that, "family members were least successful in answering items that required the application of factual knowledge, particularly in areas related to nutrition, treatment, and genetics" (Henley \& Hill, 1990, p. 1012). In addition, Henley and Hill (1990) stated that there was a significant relation between parental knowledge regarding CF and social class. Specifically, those parents rated as a lower social class were found to have less knowledge regarding CF than those rated as a higher class. Finally, Marciel (2008) stated that her results revealed that CF knowledge was not related to self-care independence; however, it was significantly associated with nurse ratings of readiness to transition. 
Chapman and Bilton (2004) suggested that low levels of knowledge regarding CF may be a result of parents' and patients' attempts to normalize CF in their lives and downplay the seriousness of the disease. Chapman and Bilton (2004) also stated that knowledge is an important factor to assess because insufficient or erroneous knowledge about $\mathrm{CF}$, and treatment regimens, may result in unintentional poor adherence. Likewise, researchers have asserted that a successful transition includes being certain that adequate information about treatment components and the disease itself is understood (Yankaskas et al., 2004). Furthermore, a study found that those with less knowledge or interest in CF were likely to be admitted to the hospital more regularly (Pinkerton, Duncan, Trauer, Hodson, \& Batten, 1985). Therefore, assessing CF knowledge as a factor related to successful transition is important. Inadequate or inaccurate knowledge regarding CF and its treatment regimen would be a major obstacle in a patient's ability to be autonomous and manage his or her own disease. Consequently, it is key to assess and identify which specific knowledge deficits patients have that may hinder their successful transition from pediatric to adult health care. Once these deficits are identified, then health professionals in the pediatric clinic can provide disease education to particular patients so that they can be more prepared to transfer from pediatric to adult-oriented centers.

\section{Summary of Relevant Literature and Rationale for Current Study}

With the advanced treatment regimens, CF patients now have a much higher predicted survival age, with most children with CF expected to live at least into middle age adult years. Thus, CF is no longer considered a "childhood" disease, and the majority of individuals diagnosed with $\mathrm{CF}$ can expect that they will require adult-oriented medical care during their lifetime (Dugueperoux et al., 2008). Consequently, this shift in survival rate illustrates the need to develop and implement transition programs that attend to the physical, developmental, and 
psychological factors of adolescents with CF who are moving from pediatric clinics to adult clinics (Webb et al., 2001). Unfortunately, many CF clinics do not yet have a transition program implemented, or, if they do, no collective guidelines currently exist to help guide health professionals on specific issues that need to be targeted (Webb et al., 2001). Moreover, little to no research has been conducted to determine the factors that may influence readiness to transition, as well as what factors may contribute to the successful transfer from pediatric to adult health care.

The majority of research related to healthcare transition with $\mathrm{CF}$ has been qualitative in nature. Specifically, the qualitative studies have used focus groups and non-validated questionnaires to report perception of patients with $\mathrm{CF}$ and their satisfaction with transition in $\mathrm{CF}$ care. These studies have reiterated the importance of transition programs in helping to alleviate the apprehension and concerns about making a successful transfer to adult care (e.g., Westwood, et al., 1999). This has resulted in researchers developing and validating measures that can be utilized to examine the $\mathrm{CF}$ transition process and its outcomes (e.g., CF Knowledge Questionnaire Siklosi et al., 2010; and Transition Readiness Assessment Questionnaire; Sawicki et al., 2009). However, even with the development of these measures, there have been few published studies that have used these or other empirically validated measures to assess readiness for transition in CF healthcare, or the transition process itself.

Hence, there is a need to develop and implement transition programs that allow adolescent/young adults with CF to make a successful and healthy transition to adult health care. First, however, research needs to be conducted to determine what behaviors and issues should be targeted in the transition programs. To date, only one study has attempted to investigate variables related to transition readiness in a quantitative manner (i.e., Marciel, 2008). Conversely, there 
have been numerous studies on how specific psychosocial variables, such as locus of control, parent boding, anxiety, and hope are associated with psychological adjustment, adherence, general functioning, and other aspects of CF. Thus, it is probable that those psychosocial factors, in addition to potential disease-related factors (e.g., knowledge), may be associated with readiness to transition. An understanding of the potential role that these factors may play in the readiness of patients with $\mathrm{CF}$ to transition from pediatric to adult healthcare will be important in the development of CF transition programs across the country. Therefore, the specific aims and hypotheses of this study are as follows:

Aim 1: Investigate the age trends in TRAQ scores.

- Hypothesis 1: Sawicki and colleagues (2009) found that older age was associated with higher scores on the TRAQ in self-management skills. Additionally, Marciel (2008) reported that in her study, the medical team rated older adolescents as having greater readiness to transition. Finally, Betz (2004) reviewed 43 transition studies conducted with adolescents diagnosed with a chronic illnesses and found that age was the main criteria used to determine when the adolescent would transfer to adult care. Thus, it is hypothesized that older developmental age (e.g., 18-20) will have higher scores in both domains (self-management and self-advocacy) than the other developmental ages (e.g., 14-15 \& 16-17), and 14-15 year olds will have the lowest scores in both domains.

Aim 2: Examine relation between parent- and youth-report of readiness.

- Hypothesis 2: A previous study investigating concordance rates between youth and parents for reports of adherence to medical regiments found that youth reported greater levels of adherence than their parents rated for them (Babyar, 2010). 
Additionally, previous studies have revealed that social desirability may influence how youth answer self-report questionnaires (e.g., Coutts et al., 1992; Marhefka et al., 2006). Consequently, it is hypothesized that youth will self-report higher readiness scores than their parents will rate for them.

Aim 3: Assess youth-rated predictors of both youth- and parent-rated readiness for transition.

- Hypothesis 3: Youth hope, internal locus of control, chance locus of control, youth anxiety, and youth CF knowledge will be associated significantly with youth- and parent-ratings of readiness. Specifically, higher levels of youth hope, higher levels of internal locus of control, lower levels of chance locus of control, lower levels of youth anxiety, and higher levels of youth CF knowledge will be associated with higher youth- and parent-ratings of readiness.

Aim 4: Examine parent predictors of both youth- and parent-rated readiness for transition.

- Hypothesis 4: Parent anxiety, perceived parental style, and parent ratings of vicarious hope for their child will be associated significantly with youth- and parent-reports of readiness. Particularly, it is hypothesized that lower levels of parental anxiety, higher levels of care in parenting, lower levels of protection in parenting, and higher levels of vicarious hope will be associated with higher youth- and parent-reports of readiness. Aim 5: Conduct exploratory analyses to evaluate whether age moderates the relation of youth and parent predictors with youth-and parent-reports of readiness.

- Hypothesis 5: Because there is no previous literature on how these factors are associated with readiness, this is an exploratory aim; therefore, a hypothesis is not generated. 
Aim 6: Determine if parental anxiety will moderate the relation between youth anxiety and readiness for transition.

- Hypothesis 6: A review of previous literature demonstrates that adolescents with CF have a higher prevalence rate of anxiety disorders than healthy controls (e.g., Boyle et al., 1976; Drotar, 1978; Modi et al., 2011; Thompson et al., 1998; White et al., 2009). Additionally, studies have found that anxious mothers are less warm in interactions with their children and do not allow their children to have as much autonomy as nonanxious mothers (e.g., Whaley et al., 1999; Woodrun-Borden et al., 2002). Finally, studies conducted with adolescents with chronic illness found that those individuals with higher anxiety were more likely to have lower treatment adherence (e.g., Herzer \& Hood, 2010; Rosina et al., 2003), and treatment adherence is one of the important components in transition readiness. Therefore, the specific hypothesis for aim 6 is that level of parental anxiety will moderate the relation between youth anxiety and youth rating of readiness to transition. Specifically, it is hypothesized that if both parents and youth rate higher levels of anxiety, then youth anxiety will have a weaker association with ratings of readiness. However, if (a) the youth rates higher levels of anxiety, and the parent rates lower levels of anxiety, or (b) the youth rates lower levels of anxiety and the parent rates higher levels of anxiety, then youth anxiety will be more strongly associated with youth-rated readiness. 


\section{Method}

\section{Participants}

A total sample of 60 participants with CF and their parents were recruited from three pediatric CF clinics (Morgantown, WV; Boston, MA; Kansas City, MO) across the United States. Specifically, children and adolescents with CF, ages 14 years to 20 years, and their parents were invited to participate in the study. Patients must have been diagnosed with CF for at least one year and both patient and caregiver must be willing to participate. However, patients were excluded from the study if they had: (a) cognitive impairment significant enough to prevent completion of study measures; or (b) already transitioned to an adult CF clinic.

\section{Procedure}

Institutional Review Board (IRB) approval was obtained for this study from the three participating CF centers prior to implementing data collection procedures at the sites.

Participation in the study took place at the patient's regularly scheduled clinic appointment or during a hospitalization, and lasted approximately 60 minutes. Clinic staff identified potential participants and asked them if they were interested in talking to research staff about the study. Then, in a private room, trained members of the research team explained the purpose of the study, the study's structure and procedures, and potential risks and benefits. Participants were assured that there would be no identifying features on the data collected and that they could withdraw from the study at any time. They also were told that the information they provided would not be shared with the CF healthcare team. Informed consent was obtained from all parents as well as patients who were aged 18-20 years, and child assent was attained from children 17 years and younger. 
The patient and their caregiver each completed a series of questionnaires. Instructions for completion were presented verbally and in writing. The packet of questionnaires for the caregiver included the following: Family Information Form (demographics \& medical information) (to be completed in conjunction with the patient, as relevant - see Appendix A), Depression Anxiety Stress Scale-21, Vicarious Futurity Scale, and Transition Readiness Assessment Questionnaire - Parent Report. The packet of questionnaires for the patients included the following: Parental Bonding Instrument, Multidimensional Health Locus of Control Scale, State-Trait Anxiety Inventory, Herth Hope Index, Transition Readiness QuestionnaireYouth Report, and Cystic Fibrosis Knowledge Questionnaire. Reading assistance was not required for any of the participants. Upon completion of the study, the patient was given a \$20 gift certificate, while the patient's parent was given a $\$ 10$ gift certificate.

\section{Measures}

Multidimensional Health Locus of Control Scale, Form C (MHLC-C; Wallston, Stein, \& Smith, 1994). The youth's beliefs about their control over their health was assessed using the MHLC-C, which is a disease specific version of the Multidimensional Health Locus of Control Scale (MHLC; Wallston, Wallston, \& DeVellis, 1978). The MHLC-C is an 18-item, conditionspecific scale where an existing medical condition is used to measure health locus of control and

all questions are answered on a 6-point Likert-type response format ( $1=$ "strongly disagree" to 6 $=$ "strongly agree"). Specifically, the measure is designed so that the researcher can insert a particular disease for the word "condition," for example, "Most things that affect my Cystic Fibrosis happen to me by chance." The questionnaire yields three subscales, including internal (six items), chance (six items), and powerful others, the latter of which has two independent subscales (doctors, 3 items; others, 3 items). The questionnaire was developed for individuals 
with an $8^{\text {th }}$ grade reading level or above, and Wallston and colleagues (1994) state that it has been successfully used with middle school aged children and above (e.g., Booth-Butterfield, Anderson, \& Booth-Butterfield, 2000; Nada-Raja, McGee, \& Williams, 1994; Radtke, Scholz, Keller, Knauper, \& Hornunt, 2010; Stanton, Nada-Raja, \& Langley, 1995; Zdanowicz, Janne, \& Reynaert, 2004).

Factor structure of Form C and reliability and validity was established in a sample of 588 patients diagnosed with either rheumatoid arthritis, chronic pain, diabetes, or cancer (Wallston et al., 1994). Cronbach's coefficient alpha for the three subscales of the MHLC-C in the development sample ranged from .67 for powerful others to .77 for internal subscales, which the authors state are adequate for research purposes. Importantly, construct validity was shown by significant and positive correlations between each of the MHLC-C subscales and their counterpart on Levenson's Multidimensional Locus of Control Scale, which the MHLC-C was modeled after (Wallston et al., 1994). Wallston and colleagues (1994) report that test-retest reliability over a 4 week period in a study on individuals with chronic pain was .80 for the internal subscale, .72 for the chance subscale, and .58 for the powerful others subscale. The total raw scores for internal and chance subscales were used in the analyses of this study. Internal consistency in this study was acceptable for both the internal $(\alpha=.70)$ and chance $(\alpha=.70)$ subscales.

State-Trait Anxiety Inventory (STAI; Spielberger, Gorsuch, Lushene, Vagg, \& Jacobs, 1983). The youth's level of anxiety was measured using the STAI. It has a $6^{\text {th }}$ grade reading level, and is designed for use with high school students, college students, and adults (Speilberger et al., 1983). This self-report measure yields two scales, each composed of 20 -items: the state scale and the trait scale. The state scale assesses how respondents currently feel, whereas the 
trait scale assesses clinical anxiety and how respondents typically feel. On the state scale, respondents choose the number that best describes the intensity of their feelings on a 4-point Likert scale ( $1=$ "not at all" to $4=$ "very much so"). On the trait scale, respondents rate the frequency of their anxiety symptoms on a 4-point Likert scale $(1=$ "almost never" to 4 = "almost always"). Scores range from a minimum of 20 to a maximum of 80 , with higher scores indicating a higher severity of anxiety.

The STAI has been used extensively in research and clinical studies in multiple disciplines, such as psychology, medicine, dentistry, education, and other social sciences. Concurrent validity was established in a sample of 900 students with correlations to scores on similar measures ranging from .60 to .73 (Spielberger et al., 1983). Additionally, test-retest reliability over a two month interval ranged from .16 to .62 and from .65 to .86 for state and trait scores, respectively (Spielberger et al., 1983). Thus, the authors stated that this measure has been accepted as a reliable and valid measure of state and trait anxiety in adolescents. For the present study, total raw scores on the trait scale were used in analyses. Cronbach's alpha for the current study was .92 .

Herth Hope Index (HHIndex; Herth, 1991). Youth's level of hope was measured using the HHIndex, an abbreviated version of Herth's initial scale, titled the Herth Hope Scale (HHS). The HHS was developed by Dufault and Martocchio (1985) who conceptualized six dimensions of hope. Herth combined those six dimensions into three subscales that were used for the item development of the HHS: cognitive-temporal, affective-behavioral, and affiliative-contextual. The HHIndex is a shorter version of the HHS to allow for greater clinical and research utility. Specifically, the HHIndex is a 12-item self-report questionnaire and questions are answered based on how much the respondent agrees with the statement on a 4-point Likert scale ("strongly 
disagree," "disagree," "agree," and "strongly agree"). Scores range from a minimum of 12 to a maximum of 48, with higher scores indicating higher levels of hope (Herth, 1991). Examples of questions include "I have short and/or long range goals," "I have a sense of direction," and "I believe my life has value and worth." The total raw score was used in the analyses of this study.

The HHIndex has been used substantially in research, including at least 40 published studies and 15 doctoral dissertations (Phillips-Salimi, Haase, Kitner, Monohan \& Azzouz, 2007). Herth (1991) initially tested the measure using a sample of 172 adult patients who were acutely ill, chronically ill or terminally ill, and found that the test-retest reliability at a two-week interval was .91 . Its reading level has been established at $6^{\text {th }}$ grade, and although originally developed for adults, has been shown to be a reliable and valid measure of hope for adolescents and young adults (Phillips-Salim et al., 2007). Furthermore, divergent validity with a hopelessness scale was established $(r=-.73)$, and concurrent validity was shown with correlations between the HHIndex and the initial HHS at $r=.92$. Overall, the measure is described as a reliable and valid instrument of measuring hope for research and clinical studies, especially in the hospital setting (Herth, 1991; Mendoza et al., 1999). In the current sample, Cronbach’s alpha was .90.

Cystic Fibrosis Knowledge and Attitudes Questionnaire. Youth's knowledge and understanding about CF was assessed with the CF Knowledge and Attitudes Questionnaire (Siklosi et al., 2010). The CF Knowledge and Attitudes Questionnaire is a 60-item multiple choice response format measure, and covers the domains of: General Knowledge and Complications, Lung and GI topics, and Reproduction and Genetics. Examples of questions include, "What is the basic problem in the body that causes the symptoms of CF," "When is physiotherapy (to clear the lungs of mucus) recommended," and "During digestion, what is the main nutrient that people with CF have trouble absorbing?" 
Siklosi and colleagues (2010) developed and validated the questionnaire using a sample of $100 \mathrm{CF}$ patients (aged 17-49). Specifically, they created an initial questionnaire using a literature review and identifying key concepts $\mathrm{CF}$ patients should know. The initial questionnaire was reviewed by a hospital-based multidisciplinary team, as well as by five individuals with $\mathrm{CF}$. Validation showed acceptable internal consistency (.75), as well as good test-retest reliability, with the retest given after 10-14 days $(r=.94)$. Criterion-related validity was achieved with a group of CF physicians and a group of medical students who were given the test; the CF physicians' mean scores were significantly higher than those for the medical students (Siklosi et al., 2010). For the current study, the total raw score was used in the analyses. Cronbach's alpha was .74 for the current sample.

The Depression Anxiety Stress Scale-21 (DASS-21; Lovibond \& Lovibond, 1995). Parent's level of anxiety was measured with the DASS-21. The DASS-21 is a 21-item, widelyused self-report screening measure for depression, anxiety, and stress in adults. All questions are answered on a 4-point Likert scale regarding how much each specific question applies to the respondent in the past week $(0=$ "did not apply to me at all" to $3=$ "applied to me very much" or "most of the time"). The DASS-21 yields a total score and three subscale scores (anxiety, depression, and stress); higher scores signify more severe symptoms. The DASS-21 is a short form of the 42-item of the Depression Anxiety Stress Scale (DASS; Lovibond \& Lovibond, 1995). Examples of questions include "I found it difficult to work up the initiative to do things," "I felt that I was using a lot of nervous energy," and "I felt that I had nothing to look forward to." Psychometric data for the DASS were established on a sample of 1,044 men and 1,870 women with an age range of 17 to 69 (Lovibond \& Lovibond, 1995). The alpha values of the sample were: Depression 0.91, Anxiety 0.84, and Stress 0.90, suggesting adequate internal 
consistency (Lovibond \& Lovibond, 1995). The DASS-21 also has been shown to have the same factor structure as the original 42-item version, as well as has shown to be a good measure to distinguish between the key features of depression, anxiety, and stress (Anthony, Bieling, Cox, Enns, \& Swinson, 1998). Additionally, Norton (2005) reported that the DASS-21 showed good test-retest reliability over a two week period $(r=.71-.81)$ and that the subscale scores demonstrated good convergent and discriminant validity. The total score on the anxiety scale was used in the analyses of this study. Cronbach's alpha for the anxiety scale in the current study was .82

Parental Bonding Instrument (PBI; Parker et al., 1979). Perceived parental style was assessed by the youth using the PBI. This measure is a 25 -item questionnaire that is one of the most widely used instruments to measure parental style (completed on separate forms for mothers and fathers), which is recalled by the youth from the first 16 years of life. The youths rate the attitudes and behaviors of their mothers, fathers, or caregivers using a 4-point Likert scale ("very like," "moderately like," "moderately unlike," "very unlike"). The measure yields two scales: care and protection. High scores on care suggest a parent who is perceived to have been warm and understanding, and low scores suggest a parent who is viewed as having been cold and rejecting. High scores on protection signify a parent who is viewed as controlling and prohibits autonomy, and low scores signify a parent who is perceived as supportive of independence. Klimidis, Minas, and Alta (1992) state that although the PBI was initially developed to be administered to adults as an instrument for measuring retrospective perceptions of their parents' behavior, the measure has been shown to maintain its underlying factor structure and internal reliability when modified to be used as a measure of current perceived parenting with adolescents. In fact, it has been widely used with a 13-17 year old population (e.g., 
Mannassis, Owens, Adam, West, \& Sheldon-Keller, 1999; McGarvey et al., 2010; Shin, Lee, Kim, \& Lee, 2012). The PBI has been used worldwide in clinical and non-clinical populations for a variety of purposes (Shin et al., 2012). The psychometric properties of the PBI scores have been shown to have a high level of test-retest reliability, internal consistency, and construct validity (Parker et al., 1979). Total raw scores for the care and protection scales were used in the analyses of this study. For the current study, the care and protection scales demonstrated good internal consistency; the Cronbach's alpha was .90 and .82 , respectively.

Vicarious Futurity Scale (VFS; Wong, Heriot, Dossetor, \& Nunn, In Press). The parents' hope for their child's future was assessed using the VFS. It is a 20-item questionnaire where parents rate how well they feel the statement describes their view of their child. All questions are answered on a 5-point Likert scale $(0=$ "not at all" to $4=$ "extremely well"). Two scores are obtained: Hope (adding all positively worded items) and Despair (adding all negatively worded items), each with a range of 0-40. Higher scores represent higher degree of hope (on Hope scale) and despair (on Despair scale). The Hope scale score was used in the analyses of this study.

The VFS was developed using questions from the HOPES instrument (Nunn, Lewtin, Walton, \& Carr, 1996) which is a measure of personal futurity. The authors reworded the items on the HOPES so that the questions were connected to the respondent's child. Examples of questions include "I generally look forward to my child's new activities and phases in their life," "I often feel that my child's future is NOT in their own hands," and "I generally believe that my child's life will be valuable and productive." Most recently, the psychometric properties of the VFS were tested on a sample of 318 parents of children (Wong et al., In Press). The researchers stated that the confirmatory factor analysis displayed the two factors of "hope" and "despair." 
Furthermore, convergent validity was found as a result of the significant positive correlations established between global vicarious hopefulness, global personal hopefulness, optimism, and self-efficacy. Finally, test-retest reliability and internal consistency of the VFS were found to be adequate (Wong et al., In Press). In the current sample, Cronbach's alpha was 0.80 .

Transition Readiness Assessment Questionnaire (TRAQ; Sawicki et al., 2009). The youth's beliefs on their readiness to move from pediatric to adult health care and their level of responsibility for their health regimen and daily life activities was measured using the TRAQ. The questionnaire has 29 items in which respondents rate their skills in the areas that are important for their medical care on a 6-point Likert type scale ("Not needed for my care," "No, I do not know how," "No, I do not know how but I want to learn," "No, but I am learning to do this," "Yes, I have started doing this," "Yes, I always do this when I need to"). Examples of questions include, "Do you reorder medications before they run out," "Do you arrange for your ride to medical appointments," and "Do you request the accommodations and support you need at school or work?"

Sawicki and colleagues (2009) developed and validated this instrument using a sample of 193 youth with special health care needs. Results of their factor analysis revealed two TRAQ domains, each with high internal consistency: Skills for Self-Management and Skills for SelfAdvocacy. Specifically, the Self-Management domain assesses skills in chronic disease self-care behaviors, such as ability to manage medication, medical appointments, and health insurance, whereas the Self-Advocacy domain assesses skills such as communication with the health care team, obtaining employment, use of community support services, and taking responsibility for financial issues. The TRAQ is the only validated "readiness" instrument in the literature and the authors state that their initial study indicates that the TRAQ is a useful tool to assess transition 
readiness in youth with special health care needs (Sawicki et al., 2009). For the present study, the TRAQ was also modified to have parent-report on youth readiness. The reference point was changed, while the structure of the questionnaire and the content of the items were not. Total raw score was used in the analyses of this study. Cronbach's alpha for the current study was .92 for the youth and .91 for parents.

Family Information Form (FIF). For the purposes of this study, a Family Information Form was devised to gather information to describe the sample and code potential covariates in statistical analyses. Consequently, questions on the FIF obtained basic demographic and medical information regarding the patient and family, such as child and parent age, ethnicity, patient and parental education, medical history, age at diagnosis, and clinic attendance. 


\section{Results}

\section{Power Analysis}

Harris (1985) states that for regression models, a minimum of ten participants per independent variable is recommended, as well as suggesting a minimum of 50 participants for a regression analysis. A power analysis was conducted with the most extensive analysis (Aim 3), which has 5 predictor variables, to estimate the sample size for this study. Using G-Power to calculate sample size with a .80 power level, a medium effect size requires 68 participants while a large effect size requires 32 participants. Because there is a lack of previous literature on variables that predict readiness for transitioning healthcare, a reasonable assumption is to anticipate a medium to large effect size. Consequently, a sample of 60 participants was the target for recruitment.

\section{Preliminary Analyses}

All data analyses were conducted through use of Predictive Analytics SoftWare Statistics 21 (PASW). To minimize missing data, research staff members were asked to review questionnaire packets prior to participants leaving the clinic. If there were missing data, participants were asked if items were intentionally left blank. The majority of patients omitted no items; however, if there were more than $20 \%$ of omitted responses on any measure, data for that measure were not to be included in analyses. No participants met this criterion. To deal with the missing data, Expectation-Maximization (EM) imputation was used. The EM imputation is a maximum likelihood-based iterative method that involves two steps. First, the E (expectation) step finds the conditional expectation of the missing data given the observed data and current estimated parameters, and then substitutes these expectations for the missing data. Second, the M (maximization) step performs maximum likelihood estimation, where the expectations formed 
with those initial values are maximized. This expectation-maximization cycle is repeated until the imputed values converge based on predetermined convergence criteria. The advantage of EM is that it is an acceptable method for a small amount of missing data (Little \& Rubin, 1987), it produces maximum-likelihood estimates of parameters and is stated to produce more accurate estimates of missing data than other strategies, such as case-wise deletion or sample mean substitution, which are generally discouraged and considered outdated (Buhi, Goodson, \& Neilands, 2008; Schafer \& Graham, 2002; Widaman, 2006). Many studies have stated that EM and multiple imputation are the two best methods for handling missing data (e.g., Peugh \& Enders, 2004). A limitation of EM is that the standard errors are not readily available and the algorithm may take a long time to converge (Little \& Rubin, 1987).

In the current study, most participants with missing data were missing only one item score on any scale (range 1-3; median 1); similarly, most parents with missing data were missing one or fewer items on any scale (range 1-5; median 1); overall, $0.05 \%$ of all items were imputed. Missing data analyses were run on all scales used in the analyses. One-way ANOVAs were conducted to examine whether scales differed based upon whether or not there were any items missing from that scale (missingness). Missingness was not found to be significantly related to the dependent variable or any auxiliary variables. Furthermore, Little's Missing Completely At Random (MCAR) test was conducted on all the items that were used in the data analyses. Little's MCAR test is a chi-square test and a significant value indicates that the data are not MCAR (Little, 1988). For the current sample, Little's MCAR test was not significant $(p=.95)$, indicating that the missing data may be assumed to be missing completely at random (Little, 1988; Tabachnick \& Fidell, 2007). 
All appropriate data screening procedures were conducted to identify possible outliers, evaluate skewness, and ensure homogeneity of variance. Additionally, due to the difference in participation rates across study sites, a series of Analyses of Variance (ANOVA) were conducted to determine whether there were any differences in the study variables based on study sites. Because this series required a total of 12 ANOVAs, a Bonferroni correction was utilized (.05/12 $=0.004)$ to set the significance level. One of the ANOVAs was significant at the $p<.004$ level. Specifically, there was a significant difference $(p<.001)$ in total family income between Boston Children's Hospital (BCH) and Children's Mercy Hospital and Clinics (CMH), as well as BCH and West Virginia University Hospitals (WVU). Thus, family income was subsequently controlled for in all analyses. Multicollinearity was assessed though Pearson correlation analyses (see Table 1). None of the correlation coefficients for the variables was greater than .80 , the value recommended by Tabachnick and Fidell (2007) to signal multicollinearity. In addition, the data were examined for outliers. Tabachnick and Fidell (2007) stated that outliers are defined as scores greater or less than 3.2 standard deviations from the mean. The examination of the data revealed no outliers for any of the scales.

Additionally, each variable was examined for normality via histogram and skewness statistic. Tabachnik and Fidell (2007) state that if the ratio of the skewness statistic to the standard error exceeds the absolute value of two, then the variable demonstrates considerable skew. The following questionnaire scores demonstrated problematic positive skew: STAI, TRAQ (parent version), DASS-21, and PBI (protection). The DASS-21, and PBI (protection) scales were transformed using square root transformation, and the TRAQ (parent version) and STAI scale required log transformations. The HHI, PBI (care), VFS, and MHLC (internal) scales demonstrated negative skew, and were transformed by taking the square root of the value 
subtracted from a constant (the largest observed value plus one). All regression analyses for Aims 3, 4, 5, and 6 were conducted twice, once each with the transformed and non-transformed variables. Because results revealed no differences, the results from the analyses using nontransformed variables are reported.

\section{Descriptive Statistics}

A total of 60 youth and 60 caregivers participated in this study. All participants were included in study analyses. A total of $16(26.7 \%)$ participants were recruited from West Virginia University (WVU) in Morgantown, WV, 16 (26.7\%) were recruited from Children's Mercy Hospitals and Clinics (CMH) in Kansas City, MO, and 28 (46.7\%) were recruited from Boston Children's Hospital $(\mathrm{BCH})$ in Boston, MA. A total of 8 participants who were approached at WVU declined to participate because they were either not interested (62.5\%), did not feel well $(12.5 \%)$, or did not want to participate that day (25\%). A total of 5 participants who were approached at $\mathrm{BCH}$ declined to participate because they were either not interested $(60 \%)$ or did not have enough time (40\%). Data for the participants who refused to participate at CMH was unavailable. Demographic characteristics of the participants and their caregivers are listed in Table 3. Youth participants consisted of 31 males, and 29 females, with a mean age of 16.48 years $(S D=1.89)$. Of the 60 youth participants, 93\% self-identified as Caucasian (non-Hispanic), $1.7 \%$ as Asian, $1.7 \%$ identified as multiracial, and 5\% left the item blank. With respect to caregiver participants, 49 were female and 11 were male. The majority of caregivers participating were mothers $(75.0 \%)$, but other caregivers included fathers $(18.3 \%)$, grandmothers (5.0\%), and grandfathers $(1.7 \%)$. Caregivers had a mean age of 47.72 years $(S D=7.59)$. An independent-samples t-test did not reveal any difference between males $(M=96.47, S D=24.69)$ and females $(M=88.26, S D=23.95 ; t(58)=1.30, p=.20)$ in self-reporting transition readiness, 
as measured by the TRAQ (Sawicki et al., 2009). Similarly, there were no differences between males $(M=79.06, S D=22.80)$ and females $(M=72.32, S D=19.86 ; t(58)=1.40, p=.17)$ in parent's ratings of their readiness; thus, youth sex was not controlled for in regression analyses.

Pearson correlation analyses (see Table 1) were conducted to examine the relations between the variables of interest (i.e., the independent variables and the youth and parent-rated TRAQ). A negative correlation was found between youth's chance locus of control and parentratings of readiness. A positive correlation was found between youth hope and youth-rated readiness, as well as between youth CF knowledge and youth-rated readiness. Of note, there was also a strong negative correlation between youth hope and youth anxiety.

Table 2 lists the mean, standard deviation, and range for all variables of interest. The mean score for youth anxiety in this study $(M=33.83)$ was similar to the mean score of another study examining trait anxiety in adolescents with CF $(M=36.39)$ (Ison, 2007). The mean score for youth internal locus of control $(M=25.47)$ and chance locus of control $(M=17.50)$ also was similar to findings in a different study assessing internal locus of control $(M=27.24)$ and chance locus of control $(M=16.72)$ in a sample of adults with CF (Hamlett et al., 1996). The mean score for youth hope $(M=40.38)$ was comparable to the mean score in a study measuring hope in adolescents diagnosed with cancer $(M=37.9)$ (Phillips-Salimi et al., 2007). Youth in this study rated their primary caregiver higher in care $(M=30.03)$ and lower in protection $(M=9.99)$ than a study investigating ratings of parental care $(M=23.60)$ and parental protection $(M=$ 14.81) in patients with Crohn's disease (Agnostini et al., 2010). Finally, the parents' mean score for vicarious hope $(M=34.18)$ was higher than the mean score $(M=24.1)$ investigating parental vicarious hope in parents with children diagnosed with Autism (Faso, Neal-Beevers, \& Carlson, 2013). 


\section{Major Analyses}

Aim/Hypothesis 1. It was hypothesized that transition readiness, as indexed by the Transition Readiness Assessment Questionnaire (Sawicki et al., 2009), will be related to age trends. Specifically, it was anticipated that older youth would have higher scores on both youthand parent-rated TRAQ scores than the other developmental ages. Two one-way between-groups ANOVAs were conducted, with youth age (14-15 years; 16-17 years; $18-20$ years) serving as the between-group factor and TRAQ scores as the dependent variable. For youth-rated readiness scores on the TRAQ, there was a statistically significant group difference: $F(2,57)=9.99, p<$ .001 . The effect size, calculated using eta squared, was 0.26 , indicating a large effect size. Posthoc comparisons using the Tukey HSD test indicated that the mean score for ages 14-15 $(M=$ $80.40, S D=23.57)$ and the mean score for ages $16-17(M=89.86, S D=23.23)$ were both significantly different from ages $18-20(M=109.15, S D=16.70)$. The two younger groups did not differ significantly from one another.

For parent-rated readiness scores on the TRAQ, there was a statistically significant difference for the three age groups: $F(2,57)=17.54, p<.001$. The effect size, calculated using eta squared, was 0.38, indicating a large effect size (Cohen, 1988). Post-hoc comparisons using the Tukey HSD test indicated that the mean score for ages $14-15(M=61.43, S D=9.61)$ and ages $15-16(M=74.76, S D=17.27)$ were both significantly different from ages $18-20(M=$ 92.44, $S D=23.45)$. Again, the two younger groups did not differ significantly from one another.

Aim/Hypothesis 2. It was hypothesized that there will be a significant difference between parent-rated and youth-rated readiness to transition, as measured by the TRAQ. Specifically youth will report higher readiness scores than their parents will rate for them regarding readiness to transition. A paired-samples t-test was conducted and the results indicated that the mean youth-readiness rating $(M=92.51)$ was significantly greater than the mean parent- 
rated readiness score for youth $(M=75.32), t(59)=6.88, p<.001$ (two-tailed). The mean difference in TRAQ scores was 17.18 with a 95\% confidence interval ranging from 12.19 to 22.18. The eta squared statistic (0.45) indicated a large effect size (Cohen, 1988).

Aim/Hypothesis 3. It was hypothesized that youth-rated variables (e.g., hope, locus of control) will significantly predict youth-and parent-ratings of readiness. For both multiple regressions, it was anticipated that higher levels of hope, higher levels of locus of control, lower levels of chance locus of control, lower levels of youth anxiety, and higher levels of youth CF knowledge as measured by the HHIndex (Herth, 1989), MHLC-C (Wallston et al., 1994), STAI (Speilberger et al., 1983), and the CF Knowledge and Attitudes Questionnaire (Siklosi, et al., 2010), respectively, would be associated with higher youth-and parent-ratings of readiness. The dependent variable for the first regression was the scores that the youth obtained on the TRAQ (Sawicki et al., 2009), whereas the dependent variable for the second regression was the parentreported scores for their youth's readiness on the TRAQ (Sawicki, et al., 2009).

First, a series of ANOVAs were conducted to determine if there were any pertinent medical and demographic variables that needed to be controlled for. The specific demographic variables investigated were: severity of symptoms, youth level of organization, youth using routines, highest level of mother education, highest level of father education, patient living at home, and if the youth sees a doctor/psychologist for behavior problems. Specifically, ANOVAs were separately conducted for each demographic variable and youth-rated transition readiness, and subsequently for each demographic variable and parent-rated transition readiness. A total of 14 ANOVAS were calculated. There was a statistically significant difference in parent-rated transition readiness scores for patient living at home: $F(1,58)=10.60, p=.002$. Specifically, patient living at home $(M=72.26, S D=20.07)$ had significantly lower parent-rated readiness 
scores than patient not living at home $(M=98.49, S D=19.77)$. Similarly, there was a statistically significant difference in youth-rated readiness scores for patient living at home: $F(1$, $58)=10.66, p=.002$. Patient living at home $(M=89.03, S D=23.30)$ had significantly lower youth-rated readiness scores than patient not living at home $(M=118.83, S D=16.49)$. None of the other ANOVAs were significant. Consequently, patient living at home was controlled for in the regression analyses. In addition, as explained earlier, family income also was controlled for in the regression analyses, as well as patient age.

The first multiple regression analysis was conducted to evaluate how well youth-rated measures predicted youth-rated transition readiness scores, after controlling for patient age, family income, and youth living at home. Age, youth living at home, and family income were entered at Step 1, explaining $36 \%$ of the variance in transition readiness. After entry of the youth predictors at Step 2, the total variance explained by the model as a whole was $49.0 \%, F(8,51)=$ $6.19, p<.001$. The youth predictors explained an additional $13 \%$ of the variance in transition readiness, after controlling for age, patient living at home, and family income, $F$ change $(5,51)=$ $2.69, p=.03$. However, in the final model, only youth age was statistically significant $(\beta=.33, p$ $=.004)$. None of the youth predictors accounted for a significant proportion of youth-rated transition readiness. Results of this first regression analysis are presented in Table 4.

Next, a multiple regression analysis was conducted to evaluate how well youth-rated measures predicted parent-rated transition readiness scores, again after controlling for age, youth living at home, and family income. Age, youth living at home, and family income were entered at Step 1, explaining 50\% of the variance in parent-rated transition readiness. After entry of the youth-rated predictors at Step 2, the total variance explained by the model as a whole was 54.2\%, $F(8,51)=7.30, p<.001$. The youth predictors only explained an additional $0.04 \%$ of the 
variance in transition readiness scores, after controlling for age, youth living at home, and family income, which was not a statistically significant change, $F$ change $(5,51)=.79, p=.56$. As presented in Table 5, in the final model, only older youth age $(\beta=.63, p<.001)$ was significantly related to increased parent-rated readiness.

Aim/Hypothesis 4. It was hypothesized that parent variables (e.g., parenting style, anxiety) will be significantly associated with youth-and parent-ratings of transition readiness. Specifically, it was hypothesized that that lower levels of parental anxiety, higher levels of care in parenting, lower levels of protection in parenting, and higher levels of vicarious hope will be associated with higher youth- and parent-reports of readiness. Again, two multiple regressions were conducted for hypothesis 4. Parent predictor variables were parental anxiety, perceived parental style, and parental hope for the youth's future, as measured by the DASS-21 (Lovibond \& Lovibond, 1995), PBI (Parker et al., 1979), and the VFS (Wong et al., In Press). The dependent variable for the first and second regression analysis was the youth- and parent-rated TRAQ score (Sawicki et al., 2009), respectively. The same demographic variables described for hypothesis 3 were controlled for in these multiple regression analyses.

The first multiple regression analysis was conducted to evaluate parent predictors of youth-rated transition readiness. Youth age, youth living at home, and family income were entered at Step 1, explaining $36 \%$ of the variance in youth-rated transition readiness. After entry of the parent predictors at Step 2, the total variance explained by the model as whole was $43.9 \%$, $F(7,52)=5.81, p<.001$. The parent predictors only explained an additional $0.08 \%$ of the variance in transition readiness scores, after controlling for age, youth living at home, and family income, which was not a statistically significant change, $F$ change $(4,52)=1.87, p=.13$. As presented in Table 6 , in the final model, older youth age $(\beta=.44, p<.001)$, less family income 
$(\beta=-.34, p<.05)$, and more parental vicarious hope $(\beta=.26, p<.05)$ were significantly related to increased youth-rated readiness.

Next, a multiple regression analysis was conducted to evaluate parent predictors of parent-rated transition readiness. Again, youth age, youth living at home, and family income were entered at Step 1, explaining 50\% of the variance in parent-rated transition readiness. After entry of the parent predictors at Step 2, the total variance explained by the model was 55.4\%, $F(7,52)=9.24, p<.001$. The parent predictors explained an additional $0.05 \%$ of the transition readiness, after controlling for youth age, youth living at home, and family income, which was not a significant change, $F$ change $(4,52)=1.53, p=0.21$. In the final model (see Table 7 ), greater youth age $(\beta=.61, p<.001)$, less family income $(\beta=-.26, p<.05)$, and greater parental vicarious hope $(\beta=.23, p<.05)$ were significantly associated with increased parent-rated readiness.

\section{Exploratory Analyses}

Aim/Hypothesis 5. Because there is a dearth of previous literature examining how psychosocial factors are associated with transition readiness, the present study sought to examine if age may moderate the relationship between the predictors and transition readiness. To test for moderation, all variables were first centered by subtracting the mean score from the original value. Next, interaction terms were created by multiplying age with each centered predictor variable. Interaction terms of age with youth hope (age x HHI), youth anxiety (age x STAI), chance locus control (age x MHLC chance), internal locus of control (age x MHLC internal), CF knowledge (age x CF knowledge), parent anxiety (age x DASS-21), parent vicarious hope (age x VFS), parent care (age x PBI care), and parent protection (age x PBI protection) were created. Exploratory hierarchical regressions were then conducted with the original youth and parent 
predictors, but each hierarchical regression also included an interaction variable. In the first step of the regression equation, youth living at home and family income were entered. In the second step, the centered age and centered youth or parent predictor were entered, and in the third step, the interaction term was entered. This was repeated for each youth and parent predictor. Significant interaction terms indicate that age is the moderator. None of the interactions were significant.

Aim/Hypothesis 6. It also was hypothesized that level of parental anxiety will moderate the relation between youth anxiety and youth rating of readiness to transition. Specifically, it was hypothesized that if both parents and youth rate higher levels of anxiety, then youth anxiety will have a weaker association with ratings of readiness. However, if (a) the youth rates higher levels of anxiety, and the parent rates lower levels of anxiety, or (b) the youth rates lower levels of anxiety and the parent rates higher levels of anxiety, then youth anxiety will be more strongly associated with youth-rated readiness. Moderation effects are best detected when the causal effect is substantial (Chaplin 1991; Frazier, Tix, \& Barron, 2004). However, moderated relationships may exist even when there are unexpectedly weak or no causal relations between predictors and dependent variables (Baron \& Kenny, 1986; Chaplin 1991). First, the predictor (youth anxiety) and moderator (parent anxiety) variables were centered. Cohen and colleagues (2003) recommend centering in analyses involving interactions of continuous variables to correct for potential multicollinearity effects. Next, product terms were formed to represent the interaction between the predictor and moderator (Frazier et al., 2004). This was accomplished by multiplying the centered predictor and the centered moderator variables together.

A hierarchical multiple regression analysis was then conducted. Youth-rated TRAQ scores were examined as the criterion variable. The control variables (age, patient living at home, 
family income) were entered in Step 1, and these variables accounted for a significant amount of variance in total youth TRAQ scores, $R^{2}=.36, F(3,56)=10.46, p<.001$. The centered predictor and moderator variable were entered in Step 2 and they did not significantly add to the amount of variance accounted for in the criterion, $\Delta R^{2}=.04, \Delta F(2,54)=1.89, p=.16$. Finally, in Step 3, the interaction term (STAI x DASS-21) was entered and it also did not account for a significant amount of additional variance in youth-rated readiness scores, $\Delta R^{2}=.01^{\prime} \Delta F(1,53)=.28, p=.60$. The interaction between youth anxiety and parental anxiety was not significantly associated with youth-rated readiness $(\beta=-.06, p=0.60)$, and consequently the sixth hypothesis was not supported. 


\section{Discussion}

Given the dearth of evidence-based CF transition programs, as well as a lack of collective guidelines to determine the best procedures for transition programs, this study aimed to explore psychosocial factors that may be associated with transition readiness for youth and young adults. At present, only one study has attempted to quantitatively investigate variables related to transition readiness (i.e., Marciel, 2008). This study differed from Marciel's by examining other psychosocial variables, and using a validated measure of transition readiness. Consequently, this study attempted to better understand potential behaviors and issues to target in transition programs. The following section will discuss the study's results, clinical implications, methodological limitations, as well as suggest ideas for future research.

\section{Examination of Proposed Hypotheses}

The hypothesis that older developmental age (18-20 year olds) would have higher scores on the transition readiness question (TRAQ) than the younger developmental ages was supported. As expected, as youth age, they are building upon their self-management and selfadvocacy skills, and are overall rated (by themselves and their parents) as having more readiness to transition than younger patients. This is a reassuring finding, because even though criteria to transfer to adult healthcare are relatively variable, the most common determining factor is age (Betz, 2004). However, research has shown that with other transitions individuals experience in their lifetime (e.g., grade school to high school, school to work, living at home to living independently), there are many factors that impact success in making those transitions (Roisman, Masten, Coatsworth, \& Tellegen, 2004). Consequently, with CF transition, relying solely on age for transition does not take into account the physical, developmental, and psychological differences between individuals, and how those may influence transition to adult health care. 
A second aim of the study was to examine the relation between youth and parent ratings of readiness to transition. Results of the Pearson correlation analyses revealed that the association between the youth and parent TRAQ was 0.65 , which is relatively high. Specifically, although there are no previous studies on concordance rate for transition readiness, the level of agreement between youth and parent reports on multidimensional health and functional status measures in chronic illness have ranged from a median correlation of 0.42 to 0.78 (Verhey et al., 2009). However, as expected, results showed that youth rate themselves as more ready to transition than their parents rate them. This outcome is consistent with previous findings that parent and youth agreement on psychological symptoms and behaviors is low (e.g., Achenbach, McConaughy, \& Howell, 1987; Cantwell, Lewinsohn, Rohde, \& Seeley, 1997) and that youth may be influenced by a degree of social desirability when answering self-report questions, and consequently rate themselves in a more positive light (Marhefka et al., 2006). The discrepancy between the youth and parent rated readiness in this study may also be explained by the fact that some parents may not closely monitor their child's behavior and medical regimen, which leads them to underestimate their child's skills and readiness. For example, a study examining concordance rates between youth and their parents regarding violence exposure found that parents underestimated the amount of times their children were victims of or witnesses to violence (Howard, Cross, Li and Huang, 1999). The authors stated that the parents that exhibited low agreement with their child were characterized by their child as being less involved, having limited communication, and low parental monitoring. This finding reiterates that information should be collected from multiple sources to decrease individual bias in reporting (Drotar, 2000), as well to as provide the most thorough and comprehensive representation of the child (Cantwell et al., 1997). Thus, when transition programs are developed, it will be important to use multiple 
information sources when monitoring the patient's progress and readiness. More objective measures of transition readiness, such as appointment attendance, pharmacy refill data, and electronic recording devices to index adherence, along with medical and parental ratings of the patient's self-management and self-advocacy skills, would be beneficial.

The next aim was to examine youth-rated predictors of both youth-and parent-rated readiness for transition to adult CF care. Because previous research has shown that the psychosocial variables used in this study (e.g., hope, locus of control, anxiety) are associated with psychological adjustment, adherence, general functioning and other aspects of chronic illness, it was hypothesized that these variables would also be associated with transition readiness. The results revealed that parental vicarious hope was significantly associated with both youth-and parent-rated transition readiness. Although there have been no previous studies as to how parental vicarious hope is associated with transition readiness or adherence, this result may be explained by the findings of Wong and Heriot (2007) who found that high parental vicarious hope and low vicarious despair were associated with better child mental health. In addition, they found that vicarious hope was a strong predictor of better parent adjustment to their child's chronic illness. Moreover, our finding is consistent with Horton and Wallander's (2001) study, which examined level of hope in parents who had children diagnosed with Type I diabetes. Specifically, they stated that parents who reported high levels of hope had greater adaptability and ability to cope with difficulties encountered in life than parents who reported low levels of hope. In addition, hope has been defined as "a positive motivational state that is based on an interactively derived sense of successful (a) agency (goal-directed energy) and (b) pathways (planning to meet goals)" (Snyder et al., 1991, p.287). Thus, individuals with higher level of hope have been found to set more achievable goals, generate more ways to reach their 
goals, and adapt to and overcome challenges impeding their goals (Snyder et al., 1991).

Consequently, parents who have higher levels of hope for their child with CF may set more future-oriented goals throughout the child's life that increases their readiness (e.g., they have a goal to have them refilling their prescription independently by a certain age). Moreover, parents may hold positive future goals for their child's adult life (e.g., believe that their child will go to college, marry, have children), which helps them generate paths to work towards those goals, which subsequently increases the child's readiness. Therefore, it is not surprising that parental vicarious hope is significantly associated with youth-and parent-rated readiness.

Results from this finding can be applied in the development of future transition programs. In particular, it would be helpful to assess parents' level of hope, and, consequently, ask those parents with lower levels of hope to participate in an intervention program that would attempt to increase their hope, emotional adjustment to the illness, and coping strategies. For example, hope therapy interventions focus on setting meaningful, achievable, and measurable goals, as well helping the individual think about one's ability to find workable routes to reach their desired goals (Cheavens, Feldman, Woodward, \& Snyder, 2006). Cheavens and colleagues (2006) report that there have been at least three experimental trials of hopeful interventions with various populations (e.g., older adults and depressed individuals) and the results of these trials reveal that hopeful thoughts can be increased. Furthermore, examining the correlations in the current study among psychosocial variables, a very strong negative correlation was found between youth hope and youth anxiety. Research on hope theory has indicated that higher hope individuals experience less depression and anxiety than individuals with lower hope (Cheavens et al., 2006). Therefore, it may also be beneficial to target youth, along with their parents, to increase level of hope. Ultimately, increasing parental vicarious hope is one method that may help increase 
youth's self-management and self-advocacy skills, and consequently, assist them in making a successful transition to adult health care.

None of the other variables (youth hope, youth anxiety, locus of control, parent anxiety, and parent care and protection) were predictive of transition readiness. However, results of the Pearson correlation analyses revealed a negative relation between youth chance locus of control and parent-rated readiness. Youth who rated higher chance locus of control were rated by their parents as being less ready to transition. This finding could be explained by a study (Neipp et al., 2007) that revealed patients were not as well adjusted to their illness if they believed that their health was determined by chance, as well as another study (Hamlett et al., 1996) that found that CF patients with higher internal LOC were more engaged in treatment adherence. It is possible that those youth with higher chance locus of control in this study do not feel that having selfmanagement and self-advocacy skills will be as important for their health outcome, and thus are rated as less ready to transition by their parents. It is also important to note that there was a lot of variance not accounted for in the multiple regression models. Thus, there could be multiple other factors not examined in this study that could play a role in transition readiness. For example, it is possible that specific provider behaviors (e.g., medical communication directed to the youth directly) are associated with transition readiness. Specifically, if providers are more encouraging of their patients transferring to adult care, versus providers that are more hesitant to have patients leave the pediatric clinic, then that could influence the patient's readiness. Interesting, results indicated a significant negative correlation between family income and transition readiness, in that parents who reported higher income were rated by both parent and youth as being less ready to transition. It is possible that parent's reporting less income do not have the same amount of time to spend with their child, thus the child is required to learn self- 
management and self-advocacy skills earlier, and consequently, they are rated as more ready to transition.

Additionally, the fifth aim of the study sought to evaluate whether youth and parent predictors are moderated by patient age, and are associated with youth-and parent-reports of readiness. However, none of the interactions were significant, suggesting that the patient age does not alter the strength or nature of the association between any of the psychosocial variables and transition readiness. While these psychosocial variables have been shown to relate to adherence, general functioning, and psychological adjustment, the hypotheses that they would also be related to transition readiness were not supported. This finding is consistent with Marciel (2008) who found that her psychosocial variables (i.e., self-care independence, executive functioning and family functioning) though different from the current study, also were not associated with ratings of readiness to transition. The current model was not consistent with the sixth hypothesis that parental anxiety moderates the relation between youth anxiety and youthrated transition readiness.

\section{Limitations}

While this study contributes to the literature on transition readiness in cystic fibrosis, it remains subject to several limitations. First, the findings are based on cross-sectional, correlational data, and causality could not be established. Specifically, given the correlational nature of the data, it is unclear, for example, whether higher parental vicarious hope leads to higher transition readiness or vice-versa. Additionally, although the instruments selected for the study are psychometrically sound, the independent and outcome variables in the study rely on self-report and parent-report, and the actual skills needed to transition (e.g. independently scheduling appointments, setting up insurance, refilling prescriptions) were not confirmed via 
medical records, pharmacy refill data, or by medical staff ratings of the patient's functioning. Moreover, the parent-rated TRAQ was modified for this study from the original self-report TRAQ, and it was found that some parents wanted a response option added to the TRAQ that would take into account that their child knew how to do the skill, but that their child chose not to perform the task. Consequently, the TRAQ, though the only published transition readiness measure, may have inherent limitations that could have affected overall study findings. In addition, youth completed the questionnaires in the clinic room, often times with their parents in the room with them. While they were assured that their data would be de-identified and that their medical team or parents would not know how they responded, they may have been concerned that others would know how they rated themselves, thus influencing their answers. Therefore, the results of the study might have been strengthened if data were collected by a number of informants and gathered in the home setting, and if social desirability was measured and controlled for in the analyses. Furthermore, only one parent/caregiver was recruited to participate in the study; this was the caregiver who happened to present to clinic at the time of study participation. The parent/caregiver participants were mainly mothers, which is not uncommon in pediatric psychology research (Phares, Lopez, Fields, Kamboukos, \& Duhig, 2005).

Consequently, this limits our understanding of how parent anxiety, vicarious hope, and parental style in other caregivers impact the youth's readiness to transition. Moreover, it is possible that some participating parents actually were not primary caregivers for their children and thus may not have been accurate reporters. Another limitation is that many of the measures demonstrated either problematic positive or negative skew. For example, the youth anxiety and parental anxiety measures were positively skewed (toward lower anxiety) and consequently, the mean score is larger than the median value. Thus, the findings may have been different if it had been a 
normatively distributed sample. Additionally, transition is an important issue for many individuals with other chronic illnesses besides cystic fibrosis, such as diabetes, juvenile rheumatoid arthritis, and sickle cell disease. However, the sample used in the study limits the ability to make generalizations to those other chronic illness groups. Finally, to be able to participate in the study, the youth had to have a parent with them who also was willing to participate. This excluded multiple youth who attended their clinic visits alone, who may have had higher ratings of readiness to transition considering that they were already attending appointments independently. Despite these limitations, the present study is one of the first studies to quantitatively study factors that may be associated with a validated measure of readiness to transition from pediatric to adult healthcare for youth with a chronic illness.

\section{Future Directions}

This study provides a necessary foundation for future research. The factors selected to be examined in this study are only a few of potentially important variables that may be correlated with transition readiness. For example, some studies have found that adolescents with chronic illnesses have the same amount or more risk-taking behaviors (e.g., alcohol, drug use, and sexual activity) than healthy adolescents (Suris \& Parera, 2005). It is possible that youth that engage in risky behaviors may be less concerned about developing self-advocacy and self-management skills essential to independently managing their illness. Thus, in future research, it would be interesting to investigate the role that other psychosocial factors may play in readiness to transition. Additionally, longitudinal data examining which risk and protective factors predict successful transition to adult health care is needed, and could provide a better understanding of causal relationships. For example, it would be interesting to evaluate different psychosocial variables (e.g., hope, anxiety, risky behaviors, etc) in individuals with CF and then measure their 
attendance to adult clinic appointments, their prescription refill rate, their employment status, and their lung functioning measurements after they transition from pediatric to adult health care. The predictive power of parental vicarious hope would also be strengthened by the use of longitudinal designs or with a larger sample size. Once research illustrates some of the factors that are related to readiness to transition, then transition programs should be developed to address these salient issues, and future research studies are needed to evaluate the transition programs for their efficacy and effectiveness.

Ultimately, the majority of children diagnosed with CF will require adult-oriented care in their lifetime. As such, transition programs are an essential component in helping patients with $\mathrm{CF}$, as well as other chronic illnesses, make a successful transfer to the adult healthcare centers. The current study provides some important results regarding the inconsistency between youth and parents' ratings of readiness, as well as information regarding the differences in readiness ratings based on developmental age. Additionally, this study highlights an important psychosocial factor that is associated with transition readiness - hope. Finally, the current study illustrates the need for continued research to examine which factors should be included in the transition programs, so that pediatric CF clinics can promote a healthy and successful transition to adult health care. 


\section{References}

Achenbach, T.M., McConaughy, S.H., \& Howell, C.T. (1987) Child/adolescent behavioral and emotional problems: Implications of cross-informant correlations for situational specificity. Psychological Bulletin, 101(2), 213-232. doi: 10.1037/0033-2909.101.2.213

Agostini, A., Rizzello, F., Ravegnani, G., Gionchetti, P., Tambasco, R., Straforini, G., Ercolani, M., \& Campieri, M. (2010). Adult attachment and early parental experiences in patients with crohn's disease. Psychosomatics: Journal of Consultation and Liaison Psychiatry, 51(3), 208-215.Retrieved from http://psy.psychiatryonline.org.www.libproxy.wvu.edu/cgi/reprint/51/3/208

Anbar, R.D., \& Murthy, V.V. (2010). Reestablishment of hope as an intervention for a patient with cystic fibrosis awaiting lung transplantation. The Journal of Alternative and Complementary Medicine, 16(9), 1007-1010. doi: 10.1089/acm.2010.0107

Anderson, D.L., Flume, P.A., Hardy, K.K., \& Gray, S. (2002). Transition programs in cystic fibrosis centers: Perceptions of patients. Pediatric Pulmonology, 33, 327-331. doi: 10.1002/ppul.10083

Andrykowski, M.A. \& Brady, M.J. (1994). Health locus of control and psychological distress in cancer patients: Interactive effects of context. Journal of Behavioral Medicine, 17(5), 439458. doi: 10.1007/BF01857919

Anthony, M.M., Bieling, P.J., Cox, B.J., Enns, M.W., \& Swinson, R.P. (1998). Psychometric properties of the 42-item versions of The Depression Anxiety Stress Scales in clinical groups and a community sample. Psychological Assessment, 10, 176-181. doi: 10.1037/10403590.10 .2 .176 
Arraras, J.I., Wright, S.J., Jusue, G., Tejedor, M., \& Calvo, J.I. (2002). Coping style, locus of control, psychological distress and pain-related behaviours in cancer and other diseases. Psychology, Health \& Medicine, 7(2), 181-187. doi: 10.1080/13548500120116139

Babyar, H.M. (2010). Informant discrepancy in cystic fibrosis: Comparison between child, parent, and physician report. Retrieved from ProQuest Digital Dissertations. (AAT 1487391)

Baron, R.M., \& Kenny, D.A. (1986) The moderator-mediator variable distinction in social psychological research: Conceptual, strategic, and statistical considerations. Journal of Personality and Social Psychology, 5, 1173-1182. doi: 10.1037/0022-3514.51.6.1173

Berge, J.M., Patterson, J.M., Goetz, D., \& Milla, C. (2007). Gender differences in young adults' perceptions of living with cystic fibrosis during the transition to adulthood: A qualitative investigation. Families, Systems, \& Health, 25(2), 190-203. doi: 10.1037/1090-7527.25.2.190

Betz, C. L. (2004). Transition of adolescents with special health care needs: review and analysis of the literature. Issues in Comprehensive Pediatric Nursing, 27(3), 179-241. Retrieved from http://informahealthcare.com/loi/cpn

Blood, G.W., Dinee, M., Kauffman, S.M. \& Raimondi, S.C. (1993). Perceived control, adjustment, and communication problems in laryngeal cancer survivors. Perceptual and Motor Skills, 77(3), 764-766. doi: 10.2466/pms.1993.77.3.764

Bloom, S.R., Kuhlthau, K., Van Cleave, J., Knapp, A.A., Newacheck, P., \& Perrin, J.M. (2012). Health care transition for youth with special health care needs. Journal of Adolescent Health, 51(3), 213-219. doi: 10.1016/j.jadohealth.2012.01.007

Booth-Butterfield, M., Anderson, R., \& Booth-Butterfield, S. (2000). Adolescents' use of tobacco, health locus of control, and self-monitoring. Health Communication, 12(2), 137148. doi: 10.1207/S15327027HC1202_2 
Bourdeau, T.L., Mullins, L.L., Carpentier, M.Y., Colletti, C.J., \& Wolfe-Christensen, C. (2007). An examination of parenting variables and child self-care behavior across disease groups. Journal of Developmental \& Physical Disabilities, 19(2), 125-134. doi: 10.1007/s10882-0079037-9

Bourjolly, J.N. (1999). Locus of control among black and white women with breast cancer: A preliminary study. Journal of Psychosocial Oncology, 7(1), 21-31. doi: 10.1300/J077v17n01_02

Boyle, I. R., di Sant'Agnese, P. A., Sack, S., Millican, F., \& Kulczycki, L. L. (1976). Emotional adjustment of adolescents and young adults with cystic fibrosis. The Journal of Pediatrics, 88, 318-326. Retrieved from http://www.jpeds.com/

Boyle, M.P., Farukhi, Z., \& Nosky, M.L. (2001). Strategies for improving transition to adult cystic fibrosis care, based on patient and parent views. Pediatric Pulmonology, 32, 428-436. doi: 10.1002/ppul.1140

Bradley, C, Lewis, K.S., Jennings, A.M. \& Ward, J.D. (1990). Scales to measure perceived control developed specifically for people with tablet-treated diabetes. Diabetic Medicine, 7 , 685-694. Retrieved from http://onlinelibrary.wiley.com/journal/10.1111/(ISSN)1464-5491

Bryden, K. S., Dunger, D. B., Mayou, R. A., Peveler, R. C., \& Neil, H. A. (2003). Poor prognosis of young adults with type 1 diabetes: a longitudinal study. Diabetes Care, 26(4), 1052-1057. Retrieved from http://care.diabetesjournals.org

Bucks, R.S., Hawkins, K., Skinner, T.C., Horn, S., Seddon, P., \& Horne, R. (2009). Adherence to treatment in adolescents with cystic fibrosis: The role of illness perceptions and treatment beliefs. Journal of Pediatric Psychology, 34(8), 893-902. doi: 10.1093/jpepsy/jsn135 
Buhi, E. R., Goodson, P., \& Neilands, T. B. (2008). Out of sight, not out of mind: Strategies for handling missing data. American Journal of Health Behavior, 32(1), 83-92. Retrieved from http://www.ajhb.org/

Callahan, S. T., \& Cooper, W. O. (2005). Uninsurance and health care access among young adults in the United States. Pediatrics, 116(1), 88-95. Retrieved from http://pediatrics.aappublications.org

Cantwell, D.P., Lewinsohn, P.M., Rohde, P., \& Seeley, J.R. (1997). Correspondence between adolescent report and parent report of psychiatric diagnostic data. Journal of the American Academy of Child and Adolescent Psychiatry, 36, 601-619. Retrieved from http://www.jaacap.com/

Cappelli, M., MacDonald, N.E., \& McGrath, P.J. (1989). Assessment of readiness to transfer to adult care for adolescents with cystic fibrosis. Child Health Care, 18(4), 218-224. doi: 10.1207/s15326888chc1804_4

Cappelli, M., McGrath, P.J., MacDonald, N.E., Boland, M., Fried, P., \& Katsanis, J. (1988). Parent, family, and disease factors as predictors of psychosocial functioning in children with cystic fibrosis. Canadian Journal of Behavioural Science, 20(4), 413-423. doi: $10.1037 / \mathrm{h} 0079938$

Chaplin, W.F. (1991). The next generation of moderator research in personality psychology. Journal of Personality, 59(2), 143-178. doi: 10.1111/j.1467-6494.1991.tb00772.x

Chapman, E., \& Bilton, D. (2004). Patients' knowledge of cystic fibrosis: Genetic determinism and implications for treatment. Journal of Genetic Counseling, 13(5), 359-385. doi: 10.1023/B:JOGC.0000044199.38694.6c 
Chaudhry, S.R, Keaton, M., \& Nasr, S.Z. (2013). Evaluation of a cystic fibrosis transition program from pediatric to adult care. Pediatric Pulmonology, 48(7), 658-665. doi: $10.1002 /$ ppul.22647

Cheavens, J.S., Feldman, D.B., Woodward, J.T., \& Snyder, C.R. (2006). Hope in cognitive psychotherapies: On working with client struggles. Journal of Cognitive Psychotherapy, 20(2), 135-145. doi: 10.1891/jcop.20.2.135

Cohen, J.W. (1988). Statistical power analysis for the behavioral sciences ( $2^{\text {nd }}$ edn). Hillsdale, NJ: Lawrence Erlbaum Associates.

Coutts, J. A., Gibson, N. A., \& Paton, J. Y. (1992). Measuring compliance with inhaled medication in asthma. Archives of Disease in Childhood, 67(3), 332-333. Retrieved from http://adc.bmj.com/

Craig, S.L., Towns, S., \& Bibby, H. (2007). Moving on from paediatric to adult health care: An initial evaluation of a transition program for young people with cystic fibrosis. International Journal of Adolescent Medicine and health, 19(3), 333-343. doi:

10.1515/ijamh.2007.19.3.333

Drotar, D. (1978). Adaptational problems children and adolescents with cystic fibrosis. Journal of Pediatric Psychology, 3(1), 45-50. doi: 10.1093/jpepsy/3.1.45

Drotar, D. (Ed.). (2000). Conducting research in pediatric and clinical child psychology. A handbook of practical strategies and methods. New York: Kluwer Academic/ Plenum Press.

Dufault, K., \& Martocchio, B. (1985). Hope: Its spheres and dimensions. Nursing Clinics of North America, 20(2), 379-391. Retrieved from http:/www.nursing.theclinics.com/

Dugueperoux, I., Tamalet, A., Sermet-Gaudelus, I., Le Bourgeois, M., Gerardin, M., DesmazesDufeu, N., \& Hubert, D. (2008). Clinical Changes of Patients with Cystic Fibrosis during 
transition from pediatric to adult care. Journal of Adolescent Health, 43, 459-465. doi: 10.1016/j.jadohealth.2008.03.005

Dupuis, F., Duhamel, F., \& Gendron, S. (2011). Transitioning care of an adolescent with cystic fibrosis: Development of systemic hypothesis between parents, adolescents, and health care professionals. Journal of Family Nursing, 17(3), 291-311. doi: 10.1177/1074840711414907

Emerson, C. S., Mollet, G. A., \& Harrison, D. W. (2005). Anxious-depression in boys: an evaluation of executive functioning. Archives of Clinical Neuropsychology, 20(4), 539-546. doi: 10.1016/j.acn.2004.10.003

Faso, D.J., Neal-Beevers, R., Carlson, C.L. (2013). Vicarious futurity, hope, and well-being in parents of children with autism spectrum disorder. Research in Autism Spectrum Disorders, 7(2), 288-297. Retrieved from http://www.sciencedirect.com/science/journal/17509467

Frazier, P.A., Tix, A.P., \& Barron, K.E. (2004). Testing moderator and mediator effects in counseling psychology research. Journal of Counseling Psychology, 51(1), 115-134. doi: 10.1037/0022-0167.51.1.115

Gladstone, GL \& Parker, GB, 2005, 'The role of parenting in the development of psychopathology: An overview of research using the parental bonding instrument', in Jennifer L. Hudson Ronald M. Rapee (ed.), Psychopathology and the Family, edn. First, Elsevier, Netherlands, 21 - 33. doi: 10.1016/B978-008044449-9/50003-4

Gortmaker, S.L., Walker, D.K., Weitzman, M., Sobol, A.M. (1990). Chronic conditions, socioeconomic risks, and behavioral problems in children and adolescents. Pediatrics, 85(3), 267-276. Retrieved from http://pediatrics.aappublications.org/ 
Greydanus, D., Patel, D., \& Pratt, H. (2010). Suicide risk in adolescents with chronic illness: Implications for primary care and specialty pediatric practice: A review. Developmental Medicine \& Child Neurology, 52, 1083-1087. doi: 10.1111/j.1469-8749.2010.03771.x

Hamlett, K.W., Murphey, M., Hayes, R., \& Doershuk, C.F. (1996). Health independence and developmental tasks of adulthood in cystic fibrosis. Rehabilitation Psychology, 41(2), 149160. doi: 10.1037/0090-5550.41.2.149

Harris, R. J. (1985). A primer of multivariate statistics (2nd ed.). New York: Academic Press. Henley, L.D., \& Hill, I.D. (1990). Errors, gaps, and misconceptions in the disease-related knowledge of cystic fibrosis patients and their families. Pediatrics, 85(6), 1008-1014. Retrieved from http://pediatrics.aappublications.org/

Herth, K. (1991). Development and refinement of an instrument to measure hope. Journal of Scholarly Inquiry in Nursing, 5(1), 39-51. Retrieved from http://www.highbeam.com/publications/scholarly-inquiry-for-nursing-practice-p166413

Herzer, M., \& Hood, K.K. (2010). Anxiety symptoms in adolescents with type 1 diabetes: Association with blood glucose monitoring and glycemic control. Journal of Pediatric Psychology, 35(4), 415-425. doi: 10.1093/jpepsy/jsp063

Holmbeck, G. N., Johnson, S. Z., Wills, K. E., McKernon, W., Rose, B., Erklin, S., \& Kemper, T. (2002). Observed and Perceived Parental Overprotection in relation to psychosocial adjustment in preadolescents with a physical disability: The mediational role of behavioral autonomy. Journal of Consulting and Clinical Psychology, 70(1), 96-110. doi:

10.1037/0022-006X.70.1.96 
Horton, T.V., \& Wallander, J.L. (2001). Hope and social support as resilience factors against psychological distress of mothers who care for children with chronic physical conditions. Rehabilitation Psychology, 46(4), 382-399. doi: 10.1037/0090-5550.46.4.382

Howard, D.E., Cross, S.I., Li, X. \& Huang, W. (1999). Parent-youth concordance regarding violence exposure: Relationship to youth psychosocial functioning. Journal of Adolescent Health, 25(6), 396-406. doi: 10.1016/S1054-139X(99)00102-0

Ievers, C.E., Brown, R.T., Drotar, D., Caplan, D., Pishevar, B.S., \& Lambert, R.G. (1999). Knowledge of physician prescriptions and adherence to treatment among children with cystic fibrosis and their mothers. Journal of Developmental and Behavioral Pediatrics, 20(5), 335343. doi: 10.1097/00004703-199910000-00008

Iles, N., \& Lowton, K. (2008). Young people with cystic fibrosis; concerns for their future: When and how should concerns be addressed, and by whom? Journal of Interprofessional Care, 22(4), 436-438. doi: 10.1080/13561820801950325

Iles, N., \& Lowton, K. (2010). What is the perceived nature of parental care and support for young people with cystic fibrosis as they enter adult health services? Health and Social Care in the Community, 18(1), 21-29. doi: 10.1111/j.1365-2524.2009.00871.x

Ison, L. L. (2007). Repressive coping style, emotional arousal, and physiological reactivity in adolescents and young adults with cystic fibrosis. Unpublished Doctoral Dissertation. University of Kentucky, Lexington, KY.

Jarrett, M. A., \& Ollendick, T. H. (2008). A conceptual review of the comorbidity of attentiondeficit/hyperactivity disorder and anxiety: Implications for future research and practice. Clinical Psychology Review, 28(7), 1266-1280. doi: 10.1016/j.cpr.2008.05.004 
Karlsson, A., Arman, M., \& Wikblad, K. (2008).Teenagers with type 1 diabetes-a phenomenological study of the transition towards autonomy in self-management. International Journal of Nursing Studies, 45(4), 562-570. Retrieved from http://www.journalofnursingstudies.com/

Kendall, P. C., \& Pimentel, S. S. (2003). On the physiological symptom constellation in youth with Generalized Anxiety Disorder (GAD). Journal of Anxiety Disorders, 17(2), 211-221. doi: 10.1016/S0887-6185(02)00196-2

Kim, D.S., Kim, H.S., Schwartz-Barcott, D., \& Zucker, D. (2006). The nature of hope in hospitalized chronically ill patients. International Journal of Nursing Studies, 43, 547-556. doi:10.1016/j.ijnurstu.2005.07.010

Klimidis, S., Minas, I., \& Alta, A. (1992). The PBI-BC: A brief current form of the Parental Bonding Instrument for adolescent research. Comprehensive Psychiatry, 33(6), 374-377. doi: $10.1016 / 0010-440 X(92) 90058-X$

Lewis, H., \& Kliewer, W. (1996) Hope, coping, psychological, and physical adjustment among children with sickle cell disease: Tests of mediator and moderator models. Journal of Pediatric Psychology, 21, 23-41. doi: 10.1093/jpepsy/21.1.25

Little, R. (1988). A test of missing completely at random for multivariate data with missing values. Journal of the American Statistical Association, 83(404), 1198-1202. Retrieved from http://www.tandfonline.com/toc/uasa20/current\#.UuE7QtIo6ig

Little, R. J. A., \& Rubin, D. B. (2002). Statistical analysis with missing data. New York: John Wiley \& Sons.

Lopez, W.L., Mullins, L.L., Wolfe-Christensen, C., \& Bourdeau, T. (2008). The relation between parental psychological distress and adolescent anxiety in youths with chronic illnesses: The 
mediating effect of perceived child vulnerability. Children's Health Care, 37, 171-182. doi: $10.1080 / 02739610802151464$

Lovibond, P.F., \& Lovibond, S.H. (1995). The structure of negative emotional states:

Comparison of the Depression Anxiety Stress Scales (DASS) with the Beck Depression and Anxiety Inventories. Behavior Research and Therapy, 33(3), 335-343. doi: 10.1016/00057967(94)00075-U

Lovibond, S. H., \& Lovibond, P. F. (1995). Manual for the Depression Anxiety Stress Scales, (2nd ed.). Sydney, Australia: Psychology Foundation of Australia.

Lowery, B.J., Jacobsen, B.S. \& DuCette, J. (1993). Causal attribution, control and adjustment to breast cancer. Journal of Psychosocial Oncology, 104, 37-53. doi: 10.1300/J077V10N04_03

Luft, G.A. (1987). Parenting style and parent-adolescent religious value consensus. Journal of Adolescent Research, 2(1), 53-68. doi: 10.1177/074355488721005

Maestripieri, D. (1999). The biology of human parenting: Insights from nonhuman primates. Neuroscience and Biobehavioral Reviews, 23(3), 411-422. Retrieved from http://www.journals.elsevier.com/neuroscience-and-biobehavioral-reviews/

Maikranz, J.M., Steele, R.G., Dreyer, M.L., Stratman A.C., \& Bovaird, J.A. (2007). The relationship of hope and illness-related uncertainty to emotional adjustment and adherence among pediatric renal and liver transplant recipients. Journal of Pediatric Psychology, 32(5), 571-581. doi: 10.1093/jpespsy/js 1046

Manassis, K., Owens, M., Adam, K.S., West, M., \& Sheldon-Keller, A.E. (1999). Assessing attachment: Convergent validity of the Adult Attachment Interview and Parental Bonding Instrument. Australian and New Zealand Journal of Psychiatry, 33(4), 559-567. doi: 10.1046/j.1440-1614.1999.00560.x 
Marciel, K. (2008). Self-care independence and readiness to transfer from pediatric to adult health care in cystic fibrosis. Unpublished Doctoral Dissertation. University of Florida, Gainesville, FL.

Marhefka, S. L., Tepper, V. J., Farley, J. J., Sleasman, J. W., \& Mellins, C. A. (2006). Brief report: Assessing adherence to pediatric antiretroviral regimens using the 24-hour recall interview. Journal of Pediatric Psychology, 31(9), 989-994. doi: 10.1093/jpepsy/jsj107

McGarvey, E. L., Keller, A., Brown, G. L., DeLonga, K., Miller, A.G., Runge, J.S., Koopman, C. (2010). Parental bonding styles in relation to adolescent males' runaway behavior. The Family Journal, 18(1), 18-23. doi: 10.1177/1066480709356545

McLaughlin, S.E., Diener-West, M., Indurkhya, A., Rubin, H., Heckmann, R., \& Boyle, M.P. (2008). Improving transition from pediatric to adult cystic fibrosis care: Lesson from a national survey of current practices. Pediatrics, 121, 1160-1166. doi: 10.1542/peds.20072217

Mendoza, T.R., Wang, X.S., Cleeland, C.S., Morrissey, M., Johnson, B.A., Wendt, J.K. (1999). The rapid assessment of fatigue severity in cancer patients: Use of the brief fatigue inventory. Cancer, 85(5), 1186-1196. doi: 10.1002/(SICI)1097-0142

Meyers, L.B., \& Meyers, F. (1999). The relationship between control beliefs and self-reported adherence in adults with cystic fibrosis. Psychology, Health \& Medicine, 4(4), 387-391. doi: $10.1080 / 135485099106135$

Miller, L., Kramer, R., Warner, V., Wickramaratne, P., Weissman, M. (1997). Intergenerational transmission of parental bonding among women. Journal of the American Academy of Child and Adolescent Psychiatry, 36(8), 1134-1139. Retrieved from http://www.jaacap.com/ 
Modi, A.C., Driscoll, K.A., Montag-Leifling, K., \& Acton, J.D. (2011). Screening for symptoms of depression and anxiety in adolescents and young adults with cystic fibrosis. Pediatric Pulmonology, 46, 153-159. doi: 10.1002/ppul.21334

Moola, F.J., \& Norman, M.E. (2011). 'Down the rabbit hole': Enhancing the transition process for youth with cystic fibrosis and congenital heart disease by re-imagining the future and time. Child: Child, Health and Development, 37(6), 841-851. Retrieved from http://onlinelibrary.wiley.com/journal/10.1111/(ISSN)1365-2214

Moore, P.S., Whaley, S.E., \& Sigman, M. (2004). Interactions between mothers and children: Impacts of maternal and child anxiety. Journal of Abnormal Psychology, 113(3), 471-476. doi: $10.1037 / 0021-843 X .113 .3 .471$

Nada-Raja, S., McGee, R., \& Williams, S. (1994). Health belief among New Zealand adolescents. Journal of Paediatrics and Child Health, 30, 523-529. Retrieved from http://onlinelibrary.wiley.com/journal/10.1111/(ISSN)1440-1754

Neipp, M.C., Lopez-Roig, S., \& Pastor, M.A. (2007). Control beliefs in cancer: A literature review. Anuario de Psicologia, 38(3), 333-355. Retrieved from http://web.ebscohost.com.www.libproxy.wvu.edu

Norton, P.J. (2007). Depression, Anxiety and Stress Scales (DASS-21): Psychometric analysis across four racial groups. Anxiety, Stress, \& Coping, 20(3), 253-265. doi: 080/10615800701309279

Nunn, K.P., Lewtin, T.J., Walton, J.M. \& Carr, V.J. (1996). The construction and characteristics of an instrument to measure personal hopefulness. Psychological Medicine, 26, 531-545. doi: $10.1017 / \mathrm{S} 0033291700035613$ 
O’Donohue, W., \& Woodward-Tolle, L. (2009). Introduction: Adolescents with chronic illness: Issues and answers. In W. O’Donohue \& L. Woodward-Tolle (Eds.), Behavior approaches to chronic disease in adolescence: A guide to integrative care (pp. 3-6). New York: Springer Science.

O’Sullivan, B.P., \& Freedman, S.D. (2009). Cystic fibrosis. The Lancet, 373(9678), 1891-1904. doi: $10.1016 / \mathrm{s} 0140-6736(09) 60327-5$

Palmer, M.L., \& Boisen, L.S. (2002). Cystic fibrosis and the transition to adulthood. Social Work in Health Care, 36(1), 45-58. doi: 10.1300/J010v36n01_04

Pao, M., \& Bosk, A. (2011). Anxiety in medically ill children/adolescent. Depression and Anxiety, 28(1), 40-49. doi: 10.1002/da.20727

Parker, G. (1990). The Parental Bonding Instrument: A decade of research. Social Psychiatry and Psychiatric Epidemiology, 25(6), 281-282. doi: 10.1007/BF00782881

Parker, G., \& Lipscombe, P. (1981). Influences on maternal overprotection. British Journal of Psychiatry, 138, 303-311. Retrieved from http://bjp.rcpsych.org/

Parker, G., Tupling, H., \& Brown, L.B. (1979). A parental bonding instrument. British Journal of Medical Psychology, 52(1), 1-10. doi: 10.1111/j.2044-8341.1979.tb02487.x

Peugh, J., \& Enders, C., (2004). Missing data in educational research: A review of reporting practices and suggestions for improvement. Review of Educational Research, 74(4), 535-556. doi: 10.3102/00346543074004525

Phares, V., Lopez, E., Fields, S., Kamboukos, D., \& Duhig, A.M. (2005). Are fathers involved in pediatric psychology research and treatment? Journal of Pediatric Psychology, 30(8), 631643. doi: 10.1093/jpepsy/jsi050 
Phillips-Salimi, C.R., Haase, J.E., Kinter, E.K., Monahan, P.O., \& Azzouz, F. (2007).

Psychometric properties of the Herth Hope Index in adolescents and young adults with cancer. Journal of Nursing Measurement, 15(1), 3-23. doi: 10.1891/106137407780851769

Pinkerton, P., Duncan, F., Trauer, T., Hodson, M.E., \& Batten, J. C. (1985). Cystic fibrosis in adult life: A study of coping patterns. Lancet, 326(8458), 761-763. doi:10.1016/S0140$6736(85) 90638-5$

Radtke, T., Scholz, U., Keller, R., Knauper, B., \& Hornunt, R. (2011). Smoking-specific compensatory health beliefs and the readiness to stop smoking in adolescents. British Journal of Health Psychology, 16(3), 610-625. doi: 10.1348/2044-8287.002001

Reid, G. J., Irvine, M. J., McCrindle, B. W., Sananes, R., Ritvo, P. G., Siu, S. C., \& Webb, G. (2004). Prevalence and correlates of successful transfer from pediatric to adult health care among a cohort of young adults with complex congenital heart defects. Pediatrics, 113(3), 197-205. Retrieved from http://pediatrics.aappublications.org

Roddenberry, A., \& Renk, K. (2010). Locus of control and self-efficacy: Potential mediators of stress, illness, and utilization of health services in college students. Child Psychiatry Human Development, 41, 353-370. doi: 10.1007/s10578-010-0173-6

Roisman, G.I., Masten, A.S., Coatsworth, J.D., \& Tellegen, A. (2004). Salient and emerging tasks in the transition to adulthood. Child Development, 75(1), 123-133. doi: 10.1111/j.14678624.2004.00658.x

Rosina, R., Crisp, J, \& Steinbeck, K. (2003). Treatment adherence of youth and young adults with and without a chronic illness. Nursing \& Health Sciences, 5(2), 139-147. doi: 10.1046/j.1442-2018.2003.00149.x 
Rotter, J.B. (1966) Generalized expectancies for internal versus external control of reinforcement. Psychological Monographs, 80(1), 1-28. doi: 10.1037/h0092976

Sawicki, G.S., Lukens-Bull, K., Yin, X., Demars, N., Huang, I., Livingwood, W., Reiss, J., \& Wood, D. (2009). Measuring the transition readiness of youth with special healthcare needs: Validation of the TRAQ- Transition Readiness Assessment Questionnaire. Journal of Pediatric Psychology, 36(2), 160-171. doi: 10.1093/jpepsy/jsp128

Schafer, J. L., \& Graham, J. W. (2002). Missing data: Our view of the state of the art. Psychological Methods, 7(2), 147-177. doi: 10.1037/1082-989X.7.2.147

Seigel, W.M., Golden N.H., Gough, J.W., Lashley, M.S., \& Sacker, I.M. (1990). Depression, self-esteem, and life events in adolescents with chronic diseases. Journal of Adolescent Health Care, 11, 501-504. Retrieved from http://www.sciencedirect.com/science/journal/01970070

Shin, H., Lee, J., Kim, B, \& Lee, S.M. (2012). Students' perceptions of parental bonding styles and their academic burnout. Asia Pacific Education Review, 13(3), 509-517. doi: $10.1007 / \mathrm{s} 12564-012-9218-9$

Siklosi, K.R., Gallaher, C.G., McKone, E.F. (2010). Development, validation, and implementation of a questionnaire assessing disease knowledge and understanding in adult cystic fibrosis patients. Journal of Cystic Fibrosis, 9, 400-405. doi: 10.1016/j.jcf.2010.07.001 Simmonds, N.J., Cullinan, P., \& Hodson, M.E. (2009). Growing old with cystic fibrosis - the characteristics of long-term survivors of cystic fibrosis. Respiratory Medicine, 103, 629-635. doi: 10.1016/j.rmed.2008.10.011 
Simmons, R.J., Goldberg, S., Washington, J., Fischer-Fay, A., \& Maclusky, I. (1995). Infantmother attachment and nutrition in children with cystic fibrosis. Journal of developmental and behavioral pediatrics, 16, 183-186. doi: 10.1097/00004703

Smith, C.A., Dobbins, C.J., \& Wallston, K.A. (1998) The meditational role of perceived competence in psychological adjustment to rheumatoid arthritis. Journal of Applied Social Psychology, 21, 1218-1247. doi: 10.1111/j.1559-1816.1991.tb00467.x

Snyder, C.R., Irving, L.M., \& Anderson, J.R. (1991). Hope and health. In C.R. Snyder, \& D.R. Forsyth (Eds.), Handbook of social and clinical psychology: The health perspective (pp. 285305). Elmsford, NY: Pergamon Press.

Spielberger, C. D., Gorsuch, R. L., Lushene, R., Vagg, P. R., \& Jacobs, G. A. (1983). Manual for the State-Trait Anxiety Inventory (Form Y). Palo Alto, CA: Consulting Psychologists Press.

Stanton, W.R., Nada-Raja, S., \& Langley, J. (1995). Stability in the structure of health locus of control among adolescents. Britisch Journal of Clinical Psychology, 34, 279-287. doi: 10.1111/j.2044-8260.1995.tb01462.x

Strausbaugh, S.D., \& Davis, P.B. (2007). Cystic Fibrosis: A review of epidemiology and pathobiology. Clinics in Chest Medicine, 28, 279-288. doi: 10.1016/j.ccm.2007.02.011

Suris, J.C., \& Parera, N. (2005). Sex, drugs and chronic illness: Health behaviours among chronically ill youth. European Journal of Public Health, 15(5), 484-488. Retrieved from http://eurpub.oxfordjournals.org/

Tabachnick, B.G., \& Fidell, L.S. (2007). Using Multivariate Statistics (4 ${ }^{\text {th }}$ Edition). Needham Heights, MA: Allyn \& Bacon.

Thompson, R.J., Gustafson, K.E., Gil, K.M., Godfrey, J., \& Bennett Murphy, L.M. (1998). Illness specific patterns of psychological adjustment and cognitive adaptational processes in 
children with cystic fibrosis and sickle cell disease. Journal of Clinical Psychology, 54(1), 121-128. Doi: 10.1002/(SICI)1097-4679(199801)54:1<121::AID-JCLP14>3.0.CO;2-M

Tuchman, L.K., Schwartz, L.A., Sawicki, G.S., \& Britto, M. (2010). Cystic fibrosis and transition to adult medical care. Pediatrics, 125(3), 566-573. doi: 10.1542/peds.2009-2791

Tuchman, L.K., Slap, G.B., \& Britto, M.T. (2008). Transition to adult care: Experiences and expectations of adolescents with a chronic illness. Child: Care, Health and Development, 34(5), 557-563. doi:10.1111/j.1365-2214.2008.00844.x

van Staa, A.L., Jedeloo, S., van Meeteren, J., \& Latour, J.M. (2011). Crossing the transition chasm: Experiences and recommendations for improving transitional care of young adults, parents and providers. Child: Care, Health, and Development, 37(6), 821-832. doi: 10.1111/j.1365-2214.2011.01261.x

Wallston, K. A., Stein, M. J., \& Smith, C. A. (1994). Form C of the MHLC Scales: A conditionspecific measure of locus of control. Journal of Personality Assessment, 63, 534-553. doi: 10.1207/s15327752jpa6303_10

Wallston, K. A., Wallston, B. S., \& DeVellis, R. (1978). Development of the Multidimensional Health Locus of Control (MHLC) scales. Health Education Monographs, 6, 160-170.

Walters., S., \& Mehta, A. (2007). Epidemiology of cystic fibrosis. In M. Hodson, D. Geddes \& A. Bush (Eds.), Cystic Fibrosis (pp. 21-45). London: Edward Arnold Ltd.

Webb, A.K., Jones, A.W., \& Dodd, M.E. (2001). Transition from paediatric to adult care: Problems that arise in the adult cystic fibrosis clinic. Journal of the Royal Society of Medicines, 40(94), 8-11. Retrieved from http://jrs.sagepub.com/ 
Weiland, S.K., Pless, I.B., \& Roghmann, K.J. (1992). Chronic illness and mental health problems in pediatric practice: results from a survey of primary care providers. Pediatrics, 89, 445-449. Retrieved from http://pediatrics.aappublications.org/

Welsh, M. J., \& Smith, A.E. (1995) Cystic fibrosis. Scientific American, 273(6), 52-59. Retrieved from http://www.scientificamerican.com/

Westwood, A., Henley, L.D., \& Willcox, P. (1999). Transition from paediatric to adult care for persons with cystic fibrosis: Patient and parent perspectives. Journal of Paediatrics and Child Health, 35, 442-445.

Whaley, S. E., Pinto, A., \& Sigman, M. (1999). Characterizing interactions between anxious mothers and their children. Journal of Consulting and Clinical Psychology, 67(6), 826 - 836. doi: 10.1037/0022-006X.67.6.826

White, T., Miller, J., Smith, G.L., \& McMahon, W.M. (2009). Adherence and psychopathology in children and adolescents with cystic fibrosis. European Child \& Adolescent Psychiatry, 18, 96-10. doi: 10.1007/s00787-008-0709-S

Widaman, F. K. (2006). Missing data: What to do with or without them. Monographs of the Society for Research in Child Development, 71(3), 42-64. doi: 10.1111/j.1540$5834.2006 .00404 . x$

Wiehe, M., \& Arndt, K. (2010). Cystic fibrosis: A systems review. American Association of Nurse Anesthetists, 78(3), 246-251. Retrieved from http://www.aana.com/newsandjournal/pages/aanajournalonline.aspx Woodgate, R.L. (1998). Adolescents' perspectives of chronic illness: "It's hard". Journal of Pediatric Nursing, 13(4), 210-233. Retrieved from http://www.pediatricnursing.org/ 
Woodruff-Borden, J., Morrow, C., Bourland, S., \& Cambron, S. (2002). The behavior of anxious parents: Examining mechanisms of transmission of anxiety from parent to child. Journal of Clinical Child and Adolescent Psychiatry, 31, 364 -374. doi:

10.1207/S15374424JCCP3103_08

Wong, M.G., \& Heriot, S.A. (2007). Parents of children with cystic fibrosis: How they hope, cope and despair. Child: Care, Health and Development, 34(3), 344.354. doi:10.1111/j.13652214.2007.00804.x

Wong, M.G., Heriot, S.A., Dossetor, D., \& Nunn, K. (In press). Hope and Vicarious Futurity.

Verhey, L.H., Kulik, D.M., Ronen, G.M., Rosenbaum, P., Lach, L., Streiner, D.L. (2009). Quality of life in childhood epilepsy: What is the level of agreement between youth and their parents? Epilepsy \& Behavior, 14(2), 407-410. doi: 10.1016/j.yebeh.2008.12.008

Yankaskas, J.R., Marshall, B.C., Sufian, B., Simon, R.H., \& Rodman, D. (2004). Cystic fibrosis adult care: Consensus conference report. Chest, 125(1), 1-39. Retrieved from http://journal.publications.chestnet.org/

Zdanowicz, N., Janne, P., \& Reynaert, C.H. (2004). Family, health, and adolescence. Psychosomatics: Journal of Consultation and Liaison Psychiatry, 45(6), 500-507. doi: 10.1176/appi.psy.45.6.500 
Table 1

Correlations between predictor and outcome variables.

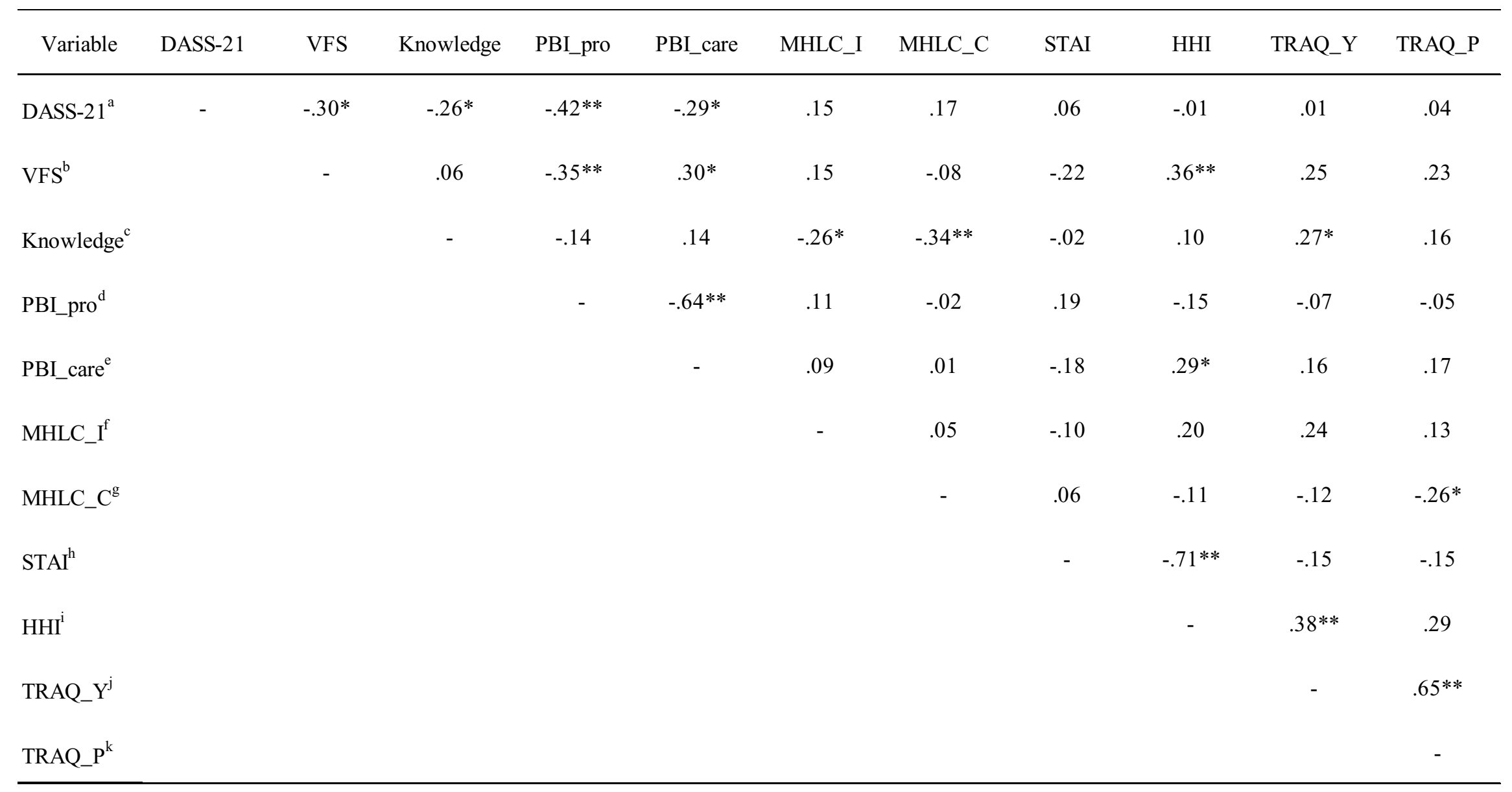

Note. ${ }^{*} p<.05 ;{ }^{* *} p<.001$

${ }^{\mathrm{a}}$ Depression Anxiety Stress Scale - 21; ${ }^{\mathrm{b}}$ Vicarious Futurity Scale; ${ }^{\mathrm{c}}$ CF Knowledge and Attitudes Questionnaire; ${ }^{\mathrm{d}}$ Parental Bonding Instrument - Protection scale; ${ }^{\mathrm{e}}$ Parental Bonding Instrument - Care scale; ${ }^{\mathrm{f}}$ Multidimensional Health Locus of Control Form C - Internal scale; ${ }^{\mathrm{g}}$ Multidimensional Health Locus of Control Form C-Chance scale; ${ }^{\mathrm{h}}$ State-Trait Anxiety Inventory; ${ }^{\mathrm{i}}$ Herth Hope Index; ${ }^{\mathrm{j}}$ Transition Readiness Assessment Questionnaire - youth version; ${ }^{\mathrm{k}}$ Transition Readiness Assessment Questionnaire - parent version 
Table 2

Descriptive Statistics for Independent and Dependent Variables

\begin{tabular}{lccc}
\hline Variable & Mean & SD & Range \\
\hline $\begin{array}{l}\text { Herth Hope Index } \\
\text { State-Trait Anxiety Inventory }\end{array}$ & 40.38 & 5.83 & $23-48$ \\
$\begin{array}{l}\text { Multidimensional Health Locus of Control } \\
\quad \text { Chance }\end{array}$ & 33.83 & 9.72 & $20-64$ \\
$\quad$ Internal & 17.50 & 4.89 & $6-30$ \\
$\quad 25.47$ & 4.80 & $11-35$ \\
$\begin{array}{l}\text { CF Knowledge and Attitudes Questionnaire } \\
\text { Parental Bonding Instrument }\end{array}$ & 19.25 & 5.03 & $7-28$ \\
$\quad$ Care & 30.03 & 6.41 & $0-36$ \\
$\quad$ Protection & 9.99 & 6.74 & $0-29$ \\
$\begin{array}{l}\text { Parent Vicarious Futurity - Hope } \\
\text { Depression Anxiety Stress Scale -21 }\end{array}$ & 34.18 & 5.35 & $15-40$ \\
$\begin{array}{l}\text { Transition Readiness Assessment Questionnaire } \\
\quad \text { Youth }\end{array}$ & 2.62 & 3.38 & $0-14$ \\
$\quad$ Parent & 92.51 & 24.48 & $47-142$ \\
& 75.32 & 21.60 & $39-131$ \\
\hline
\end{tabular}


Table 3

Demographic Characteristics of Participants

Characteristic $\%$

Youth Sex

Male

51.7

Female

48.3

Youth Race

Caucasian

Asian

1.7

Other

1.7

Parent/Caregiver Respondent

Mother

75.0

Father

18.3

Grandmother

5.0

Grandfather

1.7

Severity of Youth's CF Symptoms Over Past 3 Months

Mild

56.7

Moderate

31.7

Severe

11.7

Does youth live at home with caregiver?

Yes

87.3

No

12.7

Mother Education

$6^{\text {th }}$ grade or less

0.0

$7^{\text {th }}, 8^{\text {th }}$, or $9^{\text {th }}$ grade

0.0

Some high school $\left(10^{\text {th }}\right.$ or $11^{\text {th }}$ grade $)$

5.3

Graduate from high school

10.5

GED

3.5

Some college (at least 1 year) or specialized training

33.3

Bachelor's degree, graduated from a 4-year college

29.8

Master's degree, doctoral degree

17.5 
Table 3 (continued)

\begin{tabular}{ll}
\hline Characteristic & $\%$ \\
\hline Father Education & 0.0 \\
$6^{\text {th }}$ grade or less & 0.0 \\
$7^{\text {th }}, 8^{\text {th }}$, or $9^{\text {th }}$ grade & 4.2 \\
Some high school $\left(10^{\text {th }}\right.$ or $11^{\text {th }}$ grade) & 25.0 \\
Graduate from high school & 29.2 \\
Some college (at least 1 year) or specialized training & 31.3 \\
Bachelor's degree, graduated from a 4-year college & 10.4 \\
Master's degree, doctoral degree & \\
Family Annual Income & 10.2 \\
Less than $\$ 10,000$ & 8.5 \\
\$10,000-\$14,999 & 0.0 \\
\$15,000-\$24,999 & 6.8 \\
\$25,000-\$34,999 & 5.1 \\
\$5,000-\$49,000 & 13.6 \\
\$75,000-\$9,999,999 & 27.1 \\
\$100,000-\$149,999 & 11.9 \\
\$150,000 or more & 16.9 \\
Parent-Report of Child Organized & \\
Not at all & 10.0 \\
Somewhat & 34.5 \\
Pretty much & 38.2 \\
Very much & 16.4 \\
& \\
Parent-Report of Child Uses Routines & \\
Not at all & 5.5 \\
Sometimes & 34.5 \\
Often & 41.8 \\
Very often & 18.2 \\
Child Seen Doctor/Psychology for Behavior Problems & \\
No & 69.0 \\
Yes & 31.0 \\
\hline
\end{tabular}


Table 4

Hierarchical regression analysis with youth-predictors and youth TRAQ scores as outcome variable.

\begin{tabular}{|c|c|c|c|c|c|}
\hline Step & Predictor & $\mathrm{R}^{2}$ & $\Delta \mathrm{R}^{2}$ & $\begin{array}{l}\text { Standardized } \\
\text { Regression } \\
\text { Coefficient }(\beta)\end{array}$ & $\begin{array}{l}\text { Significance } \\
\text { Value }(p)\end{array}$ \\
\hline \multirow[t]{4}{*}{1} & & .36 & & & \\
\hline & Child_Age & & & .43 & $.00^{* *}$ \\
\hline & Pif_13 ${ }^{\mathrm{a}}$ & & & -.24 & .05 \\
\hline & Pif_23 ${ }^{\mathrm{b}}$ & & & -.20 & .05 \\
\hline \multirow[t]{9}{*}{2} & & .49 & $.13 *$ & & \\
\hline & Child_Age & & & .33 & $.004 *$ \\
\hline & Pif_13 & & & -.20 & .08 \\
\hline & Pif_23 & & & -.20 & .07 \\
\hline & $\mathrm{HHI}^{\mathrm{c}}$ & & & .27 & .08 \\
\hline & $\mathrm{STAI}^{\mathrm{d}}$ & & & .05 & .78 \\
\hline & MHLC_C & & & -.10 & .36 \\
\hline & MHLC_I $\mathrm{I}^{\mathrm{f}}$ & & & .13 & .24 \\
\hline & Knowledge $\mathrm{e}^{\mathrm{g}}$ & & & .18 & .13 \\
\hline
\end{tabular}

Note: $* p<.05 ; * * p<.001$

${ }^{\mathrm{a}}$ Patient Information Form \# 13 does child live at home; ${ }^{\mathrm{b}}$ Patient Information Form \# 23 Family Income; ${ }^{\mathrm{c}}$ Herth Hope Index; ${ }^{\mathrm{d}}$ State-Trait Anxiety Inventory; ${ }^{\mathrm{e}}$ Multidimensional Health Locus of Control Form C-Chance scale; ${ }^{\mathrm{f}}$ Multidimensional Health Locus of Control Form C - Internal scale; ${ }^{\mathrm{g}} \mathrm{CF}$ Knowledge and Attitudes Questionnaire 
Table 5

Hierarchical regression analysis with youth-predictors and parent TRAQ scores as outcome variable.

\begin{tabular}{|c|c|c|c|c|c|}
\hline Step & Predictor & $\mathrm{R}^{2}$ & $\Delta \mathrm{R}^{2}$ & $\begin{array}{l}\text { Standardized } \\
\text { Regression } \\
\text { Coefficient }(\beta)\end{array}$ & $\begin{array}{l}\text { Significance } \\
\text { Value }(p)\end{array}$ \\
\hline \multirow[t]{4}{*}{1} & & .50 & & & \\
\hline & Child_Age & & & .60 & $.00 * *$ \\
\hline & Pif_13 ${ }^{\mathrm{a}}$ & & & -.19 & .10 \\
\hline & Pif_23 ${ }^{b}$ & & & -.16 & .07 \\
\hline \multirow[t]{9}{*}{2} & & .54 & .04 & & \\
\hline & Child_Age & & & .63 & $.00 * *$ \\
\hline & Pif_13 & & & -.18 & .09 \\
\hline & Pif_23 & & & -.16 & .13 \\
\hline & $\mathrm{HHI}^{\mathrm{c}}$ & & & -.01 & .97 \\
\hline & STAI $^{\mathrm{d}}$ & & & -.19 & .18 \\
\hline & MHLC_C ${ }^{\mathrm{e}}$ & & & -.01 & .95 \\
\hline & MHLC_I ${ }^{\mathrm{f}}$ & & & .01 & .96 \\
\hline & Knowledge $^{\mathrm{g}}$ & & & -.01 & .95 \\
\hline
\end{tabular}

Note: $* p<.05 ; * * p<.001$

${ }^{a}$ Patient Information Form - \# 13 does child live at home; ${ }^{b}$ Patient Information Form - \# 23

Family Income; ${ }^{\mathrm{c}}$ Herth Hope Index; ${ }^{\mathrm{d}}$ State-Trait Anxiety Inventory; ${ }^{\mathrm{e}}$ Multidimensional Health Locus of Control Form C-Chance scale; ${ }^{\mathrm{f}}$ Multidimensional Health Locus of Control Form CInternal scale; ${ }^{\mathrm{g}} \mathrm{CF}$ Knowledge and Attitudes Questionnaire 
Table 6

Hierarchical regression analysis with parent-predictors and youth TRAQ scores as outcome variable.

\begin{tabular}{|c|c|c|c|c|c|}
\hline Step & Predictor & $\mathrm{R}^{2}$ & $\Delta \mathrm{R}^{2}$ & $\begin{array}{l}\text { Standardized } \\
\text { Regression } \\
\text { Coefficient }(\beta)\end{array}$ & $\begin{array}{l}\text { Significance } \\
\text { Value }(p)\end{array}$ \\
\hline \multirow[t]{4}{*}{1} & & .36 & & & \\
\hline & Child_Age & & & .44 & $.00 * *$ \\
\hline & Pif_13 ${ }^{\mathrm{a}}$ & & & -.23 & .05 \\
\hline & Pif_23 ${ }^{b}$ & & & -.23 & .05 \\
\hline \multirow[t]{8}{*}{2} & & .44 & .08 & & \\
\hline & Age & & & .44 & $.00 * *$ \\
\hline & Pif_13 & & & -.17 & .16 \\
\hline & Pif_23 & & & -.34 & $.01 *$ \\
\hline & PBI_care ${ }^{c}$ & & & .07 & .62 \\
\hline & PBI_pro ${ }^{\mathrm{d}}$ & & & -.05 & .72 \\
\hline & $\mathrm{VFS}^{\mathrm{e}}$ & & & .26 & $.03 *$ \\
\hline & $\mathrm{DASS}^{\mathrm{f}}$ & & & -.02 & .91 \\
\hline
\end{tabular}

Note: ${ }^{*} p<.05 ; * * p<.001$

${ }^{a}$ Patient Information Form - \# 13 does child live at home; ${ }^{b}$ Patient Information Form - \# 23 Family Income; ${ }^{\mathrm{c}}$ Parental Bonding Instrument - Care scale; ${ }^{\mathrm{d}}$ Parental Bonding Instrument Protection scale; ${ }^{\mathrm{e}}$ Vicarious Futurity Scale $;{ }^{\mathrm{f}}$ Depression Anxiety Stress Scale -21 
Table 7

Hierarchical regression analysis with parent-predictors and parent TRAQ scores as outcome variable.

\begin{tabular}{|c|c|c|c|c|c|}
\hline Step & Predictor & $\mathrm{R}^{2}$ & $\Delta \mathrm{R}^{2}$ & $\begin{array}{l}\text { Standardized } \\
\text { Regression } \\
\text { Coefficient }(\beta)\end{array}$ & $\begin{array}{l}\text { Significance } \\
\text { Value }(p)\end{array}$ \\
\hline \multirow[t]{4}{*}{1} & & .50 & & & \\
\hline & Child_Age & & & .60 & $.00 * *$ \\
\hline & Pif_13 ${ }^{\mathrm{a}}$ & & & -.19 & .10 \\
\hline & Pif_23 $3^{b}$ & & & -.16 & .07 \\
\hline \multirow[t]{8}{*}{2} & & .55 & .05 & & \\
\hline & Age & & & .61 & $.00 * *$ \\
\hline & Pif_13 & & & -.14 & .19 \\
\hline & Pif_23 & & & -.26 & $.03 *$ \\
\hline & PBI_care ${ }^{c}$ & & & .04 & .76 \\
\hline & PBI_pro ${ }^{\mathrm{d}}$ & & & -.02 & .88 \\
\hline & $\mathrm{VFS}^{\mathrm{e}}$ & & & .23 & $.03 *$ \\
\hline & $\mathrm{DASS}^{\mathrm{f}}$ & & & -.06 & .58 \\
\hline
\end{tabular}

Note: ${ }^{*} p<.05 ;{ }^{* *} p<.001$

${ }^{\mathrm{a}}$ Patient Information Form - \# 13 does child live at home; ${ }^{\mathrm{b}}$ Patient Information Form - \# 23 Family Income; ${ }^{\mathrm{c}}$ Parental Bonding Instrument - Care scale; ${ }^{\mathrm{d}}$ Parental Bonding Instrument Protection scale; ${ }^{\mathrm{e}}$ Vicarious Futurity Scale; ${ }^{\mathrm{f}}$ Depression Anxiety Stress Scale -21 


\section{Appendix A}

Family Information Form

PARTICIPANT \#

TODAY'S DATE:

\section{PATIENT INFORMATION FORM}

Note: This form should be completed by PARENT, with the help of the patient. Please answer the following questions as well as you can. If you have any problems, please ask the researcher for some help.

PATIENT/CHILD INFORMATION:

AGE:

SEX (circle): $\quad$ Male Female

RACE (circle): White African-American

Asian

Native Hawaiian or Other Pacific Islander

American Indian,

Alaskan Native

Other:

ETHNICITY (circle): Hispanic or Latino Not Hispanic or Latino

GRADE: In college (circle one)? YES NO

IS YOUR CHILD CURRENTLY WORKING (circle one)? No Part-Time Full-Time

1. At what AGE was your child first diagnosed with CF (please specify whether it is months or years)

2. Does your child have any relatives (family members) with CF?

No Yes If YES, list ALL of them (mother, grandfather, cousin, etc.): 
Please describe the medicines your child takes for his or her CF:

\begin{tabular}{|l|l|l|l|}
\hline Name of Medicine & Dose (amount) & $\frac{\text { Schedule (morning, night, }}{\text { twice a day, with meals) }}$ & $\frac{\text { Method (neb, inhaler, }}{\text { pills, liquid) }}$ \\
\hline & & & \\
\hline & & & \\
\hline & & & \\
\hline & & & \\
\hline
\end{tabular}

4. Please describe the airway clearance technique (for example: vest, Acapella, chest percussion, Flutter) your child is doing for his or her CF:

\begin{tabular}{|c|c|c|c|}
\hline$\frac{\text { Type of Airway }}{\text { Clearance }}$ & $\frac{\text { Minutes or Cycles }}{\text { (please specify) }}$ & $\frac{\text { Schedule (morning, }}{\text { night, twice a day) }}$ & $\frac{\text { \# Positions (if you }}{\text { are clapping) }}$ \\
\hline & & & \\
\hline & & & \\
& & & \\
\hline
\end{tabular}

5. What specific dietary recommendations has your child received for his/her CF?

6. Describe other treatments your child takes/does for other illnesses: 
7. Are there any other CF treatments (medication or airway clearance technique) that your child has been told to do, but is NOT currently doing? If yes, please list below.

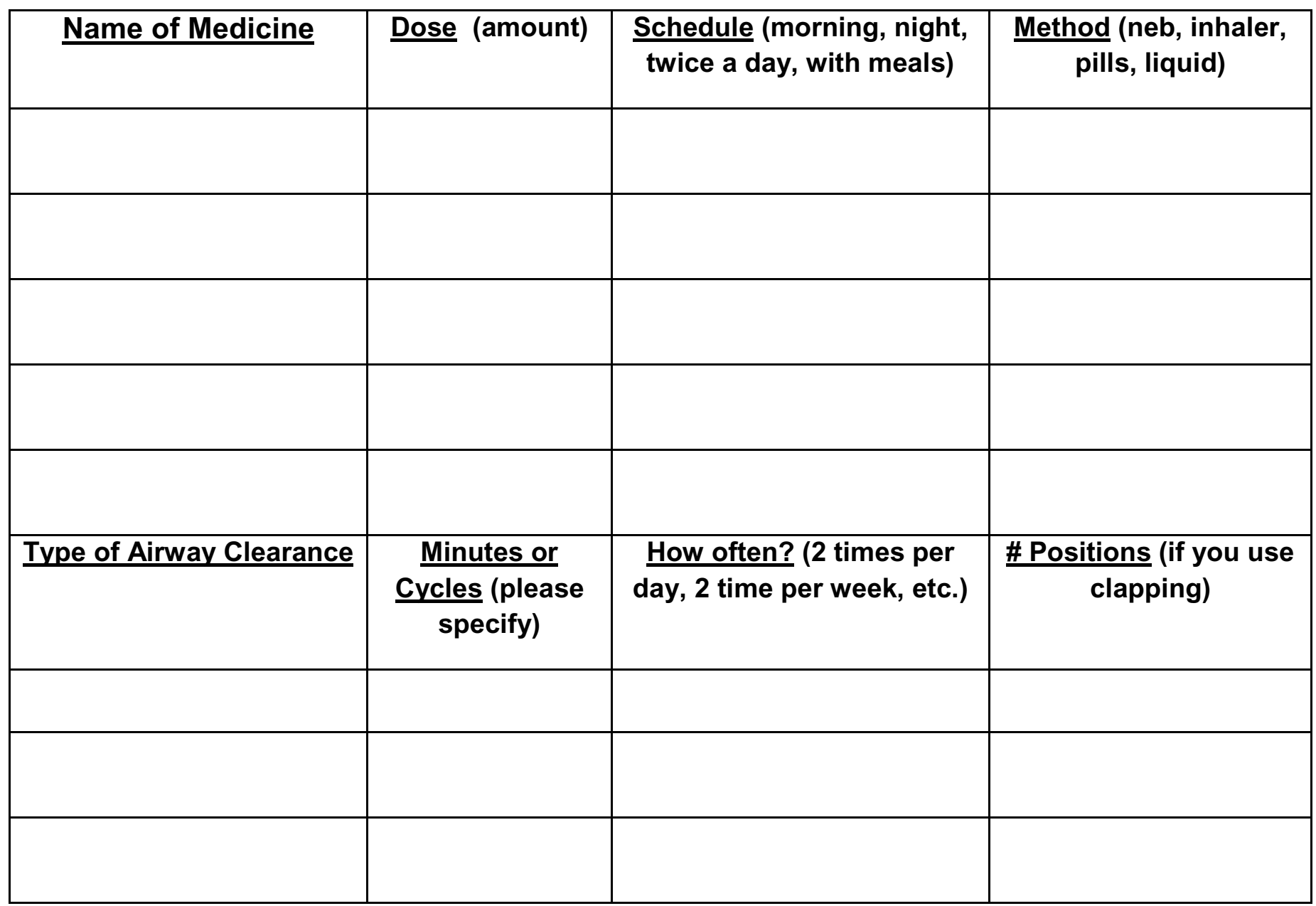

8. How intense/severe have your child's CF symptoms been OVER THE PAST 3 MONTHS? (circle one)

Mild Moderate Severe

9. Does your child have any illnesses other than CF?

$$
\text { No _-_-_ Yes }
$$

(Please List: 
10. Has your child received any kind of special education services for learning problems?

No _-_-_ Yes

(In what grades?

(For what type of problem?

11. Has your child ever seen a doctor or psychologist for behavioral or emotional problems?

No __-_-_ Yes

(For what diagnosis/ problems?

12. What type of health insurance does your child have? Please list all.

13. Does your child live at home with you?

Yes

No

If no, where does your child live (e.g., dorm, own apartment, relative's house)?

If no, who does your child live with (e.g. grandparents, friend, roommate, no one)?

14. Is your child involved in CF support groups online?

Yes _-_-_-_ No

If yes, which one(s)? 
15. How organized in your child, in general? Circle your answer.
Not at all
Somewhat
Pretty much
Very much

16. How often does your child use routines, in general, during his or her day? Circle your answer.

Not at all Sometimes Often Very Often

FAMILY INFORMATION:

17. WHAT IS YOUR RELATIONSHIP TO THE CHILD (for example: mother, grandparent)?

YOUR AGE:

18. Who is the Primary caregiver for the child? In other words, which adult (e.g., mother, father, grandmother) takes primary responsibility for helping your child take care of his or her CF?

19. Please make a check in front of each family member that is CURRENTLY living in your child's home.

Biological Mother

Adoptive or Step-Mother

Brother (How many?

Grandparent (How many?

Other (list by relationship to child)
Biological Father

Adoptive or Step-Father

Sister (How many?

20. Please make a check in front of your marital status.

Never Been Married / Single

Married to other biological parent

Living with boyfriend / girlfriend
Divorced / Single

Remarried to step-parent

Widowed (other biological

parent is deceased) 
For the rest of the questions, please list/describe those people (typically, the parents) that PROVIDE FOR THE HOUSEHOLD (help to pay bills, buy food, buy clothes, etc.).

$1=6$ th grade or less

$2=7$ th, 8 th, or 9th grade

$3=\quad$ Some high school (10th or 11th grade)

$4=$ Graduate from high school

$5=\quad$ Some college (at least 1 year) or specialized training (example:

Vocational)

$6=$ Bachelor's degree, graduated from a 4-year college (KU, UMKC, MU, etc.)

$7=\quad$ Master's degree, doctoral degree

21. Using the above scale in the box, please show the highest level of education completed by the people who PROVIDE for the CHILD (help pay bills, buy food, buy clothes). If the person listed is NOT the mother or father of the child, please write who this person is (for example: step-parent, grandparent) next to it.

Mother $=$

Father $=$

22. Please provide a job title \& description for the persons listed in Question \# 3.

Mother (or other):

Is she employed? (circle): Not at all Part-time Full-time

Father (or other):

Is he employed? (circle): Not at all Part-time Full-time 
23. Please check your total, annual family income level:

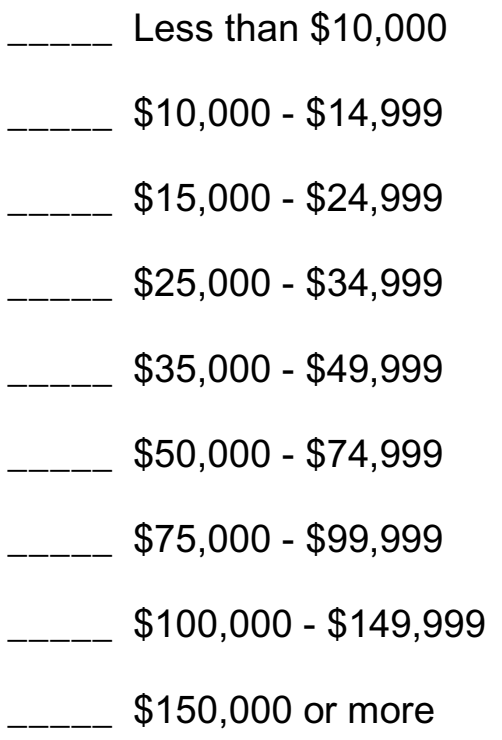

\section{Thank you!}

